\title{
Advances in Two-Line Heterosis Breeding in Rice via the Temperature-Sensitive Genetic Male Sterility System
}

\author{
Jauhar Ali, Madonna Dela Paz, and Christian John Robiso
}

\begin{abstract}
Hybrid rice technology is a viable strategy to increase rice production and productivity, especially in countries with limited cultivable land for agriculture and irrigation water, along with costlier chemical inputs. The three-line hybrid rice technology adoption rate is slowing down because of restricted heterosis per se, the availability of better combining ability in cytoplasmic male sterile lines, lower hybrid seed reproducibility, and limited market acceptability of hybrids. Two-line heterosis breeding could overcome these shortcomings. However, the wide-scale adoption and use of two-line hybrid rice technology are possible through systematic research and breeding efforts to develop temperature-sensitive genetic male sterile (TGMS) lines with low $\left(<24{ }^{\circ} \mathrm{C}\right)$ critical sterility temperature point, which is discussed in this chapter. Research on the genetics, breeding, grain quality, and resistance to insect pests and diseases for TGMS line development and physiological characterization is also discussed. In addition, the identification and validation of natural sites for TGMS self-seed multiplication and hybrid rice seed production through GIS mapping and climatic data analytical tools are also tackled. The development of high-yielding two-line rice hybrids and improvement in hybrid rice seed reproducibility could help in their wide-scale adoption.
\end{abstract}

Keywords Temperature-sensitive genetic male sterile (TGMS) lines · Critical sterility temperature point (CSTP) · Physiological characterization · Genetics · Rice 


\section{Introduction}

Global rice production in 2018 was 782 million tons from 167.1 million hectares with an average productivity of 4.68 t/ha (FAOSTAT 2020). However, production needs to keep pace with the increasing food demand in the coming decades, especially when the global human population is predicted to reach 9.73 billion by 2050 (Worldometer 2020). Increasing rice production under declining resources such as cultivable land and irrigation water and costlier agricultural inputs will become a great challenge in the coming decades. Furthermore, climate change is going to increase the pressure on stable and sustainable rice production.

Hybrid rice technology is a viable approach to increase rice production under limited resources and climate change. This technology took roots as early as 1964 in China, and around the same time, international scientific communities were discussing its prospects, especially in India, the United States, and the Philippines (Carnahan et al. 1972; Swaminathan et al. 1972; Athwal and Virmani 1972). However, it was China under Professor Yuan Longping that demonstrated hybrid rice technology on a commercial scale in 1976 with requisite cytoplasmic male sterile (CMS), maintainer, and restorer lines. This early success led China to expand hybrid rice significantly to reach 16.7 million ha, accounting for 57\% of the country's rice area. Hybrid rice now accounts for more than $65 \%$ of China's total national rice production. In recent years, the average productivity of rice in China has been $6.45 \mathrm{t} / \mathrm{ha}$ : $7.50 \mathrm{t} / \mathrm{ha}$ for hybrid rice and $6.15 \mathrm{t} / \mathrm{ha}$ for conventional rice. The increased production of hybrid rice each year provides food for more than 70 million people (Yuan 2014). The International Rice Research Institute (IRRI) made a significant effort to deploy hybrid rice technology outside China by sharing the requisite hybrid rice parental lines directly to both the public and private sectors. Parental lines developed by IRRI have been used quite extensively in the release of several commercial hybrids from the private and public arenas in India, Nepal, Pakistan, Vietnam, the Philippines, Bangladesh, and Indonesia. IRRI has directly released 17 hybrids in the Philippines alone.

Despite the enormous research and extension efforts that have gone into hybrid rice from the early 1990s, especially in Asia, hybrid rice area is growing slowly. Among the major reasons for the slow growth is, first, the available level of heterosis or hybrid rice yield advantage over the best checks is from $15 \%$ to $20 \%$. Second, hybrid rice seed reproducibility is still below $2 \mathrm{t} /$ ha for most hybrids outside China, besides being cumbersome and expensive, which is not attractive to the private seed industry to adopt the technology on a wide scale. Third, hybrids do not possess the required amount of disease and insect pest resistance in the target regions. Fourth, the grain quality of hybrids does not meet market needs, and decreased head rice recovery is keeping farmers from adopting hybrid rice. In addition, the rapid rise in labor wages in India and China is causing the seed industry to look for alternative approaches to decrease the cost of hybrid rice seed and make it more efficient based on parental line improvement to entice farmers to adopt hybrid rice and benefit. In this regard, the Hybrid Rice Development Consortium (HRDC) at IRRI is consider- 
ing these factors and developing market-oriented parental materials. Ongoing hybrid rice research at IRRI seeks to improve the levels of outcrossing and hybrid seed reproducibility, especially by developing newer CMS lines. The HRDC has been sharing these improved materials with both the public and private sectors in an aggressive manner since 2016. Currently, the area of hybrid rice outside China is approximately 8 million ha, and pushing hybrid rice technology is vital to overcome its shortcomings. In this context, it is crucial to revisit other alternative technologies such as two-line hybrid rice technology for efficient seed production and increased heterosis.

\section{The Emergence of Two-Line Hybrid Rice Technology with a Historical Perspective}

Two-line hybrid breeding began with the discovery of a photoperiod-sensitive genic male sterile (PGMS) mutant, Nongken 58S, in Hubei Province, China, which remains male sterile under long-day conditions ( $>13.45 \mathrm{~h}$ ) or fertile under shorter day (<13 h) conditions (Shi 1981, 1985; Shi and Deng 1986). Likewise, the discovery of thermosensitive genic male sterility (TGMS) that renders the plant male sterile at higher mean temperatures and reverts it to fertility at lower mean temperatures allowed significant development of the technology. Several TGMS sources of spontaneous or induced origin were discovered such as Annong S-1 and Anxiang S (Tan et al. 1990; Lu et al. 1994) in China, Norin PL 12 (Maruyama et al. 1990, 1991) in Japan, IR32364 at IRRI (Virmani and Voc 1991), and SM 5, F61, and SA 2 in India (Ali 1993; Ali et al. 1995; Hussain et al. 2012; Reddy et al. 2000) (Table 1). Moreover, photo-thermosensitive genic male sterility systems were also discovered, for which researchers found the interaction of photoperiod and temperature that governs male sterility-fertility alteration. Based on these three male sterility-fertility alteration systems involving photoperiod, temperature, and photo-thermo interactions, Yuan (1987) put forward a new strategy of hybrid rice breeding that did not involve a maintainer line, and it was called the two-line method. Any fertile line with a dominant gene for this trait could be used as a pollen parent to develop rice hybrids (Lu et al. 1994). Two-line hybrid rice technology has several advantages over the three-line system, including a wider range of germplasm resources as pollen parents, thus allowing opportunities to exploit higher heterosis and simpler procedures for breeding and hybrid seed production (Ali et al. 2018; Chen et al. 2020).

In tropical conditions, day length differences are marginal, and therefore, the TGMS system is more useful than the PGMS and PTGMS systems. Consistent temperature differences are found at different altitudes and over different seasons in the same location or region, which could be exploited for two-line hybrid rice development. However, successful exploitation of this novel male sterility system relies on knowledge of the fertility behavior of TGMS lines (Chandirakala et al. 2008). 


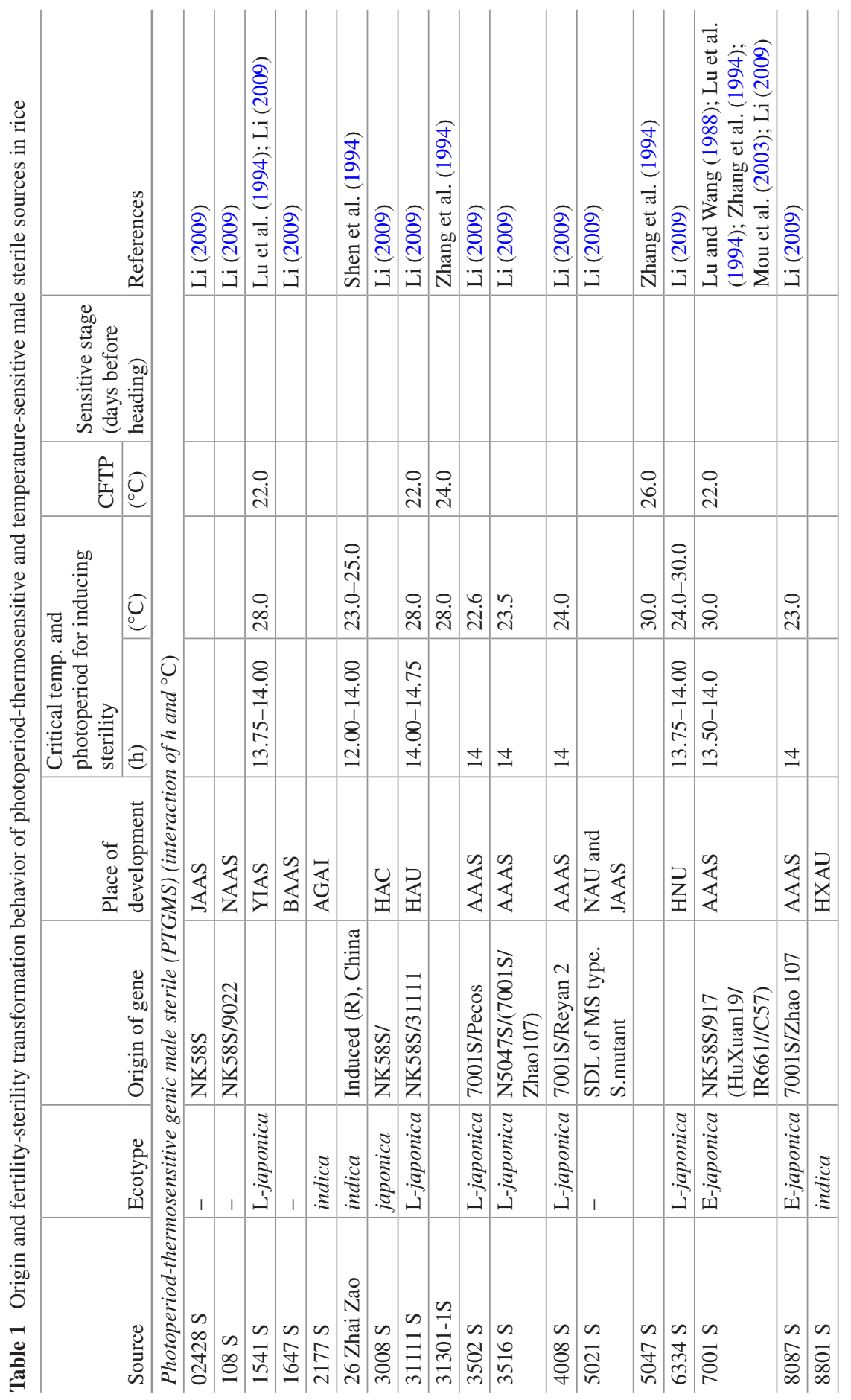




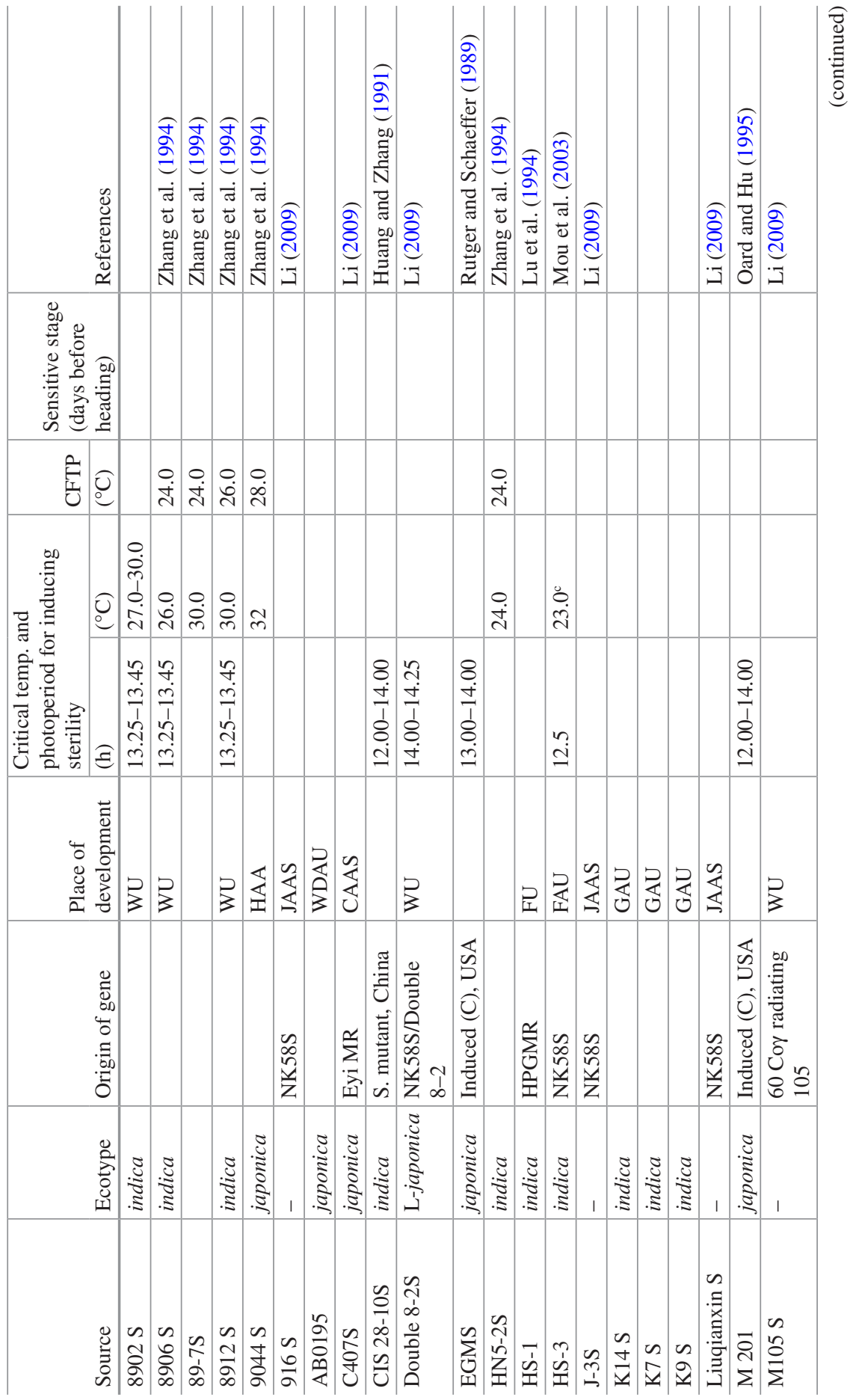




\begin{tabular}{|c|c|c|c|c|c|c|c|c|c|c|c|c|c|c|c|c|c|c|}
\hline 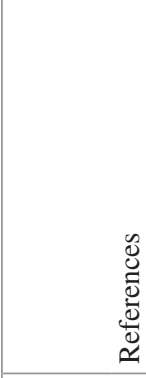 & & 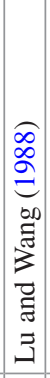 & 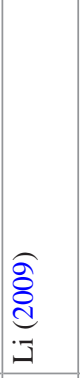 & 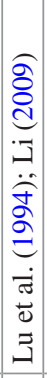 & 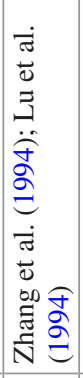 & 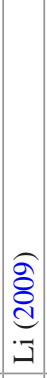 & 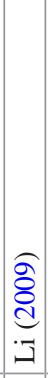 & 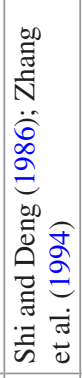 & 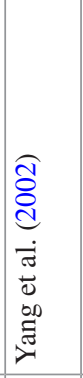 & 紊. & 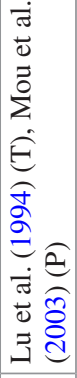 & & & 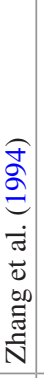 & 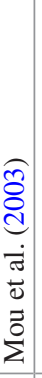 & & & 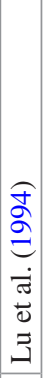 \\
\hline 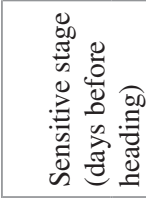 & & & & & & & & & & & & & & & & & & $\begin{array}{l}2 \\
1 \\
1 \\
0\end{array}$ \\
\hline 它 & $\stackrel{O}{\stackrel{+}{\sim}}$ & & & & 올 & & & $\stackrel{0}{\stackrel{i}{i}}$ & ì & $\begin{array}{l}0 \\
\infty \\
i \\
i\end{array}$ & & $\begin{array}{l}\stackrel{\leftrightarrow}{\dot{d}} \\
\stackrel{\mathrm{d}}{ }\end{array}$ & $\begin{array}{l}0 \\
\stackrel{\sim}{\sim}\end{array}$ & $\begin{array}{l}0 \\
\dot{J}\end{array}$ & & & & \\
\hline 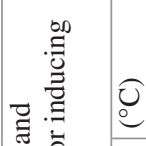 & 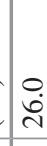 & & & 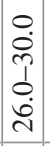 & 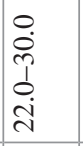 & $\begin{array}{l}0 \\
\dot{\sim} \\
\text { N }\end{array}$ & $\begin{array}{l}0 \\
\dot{d} \\
\text {. }\end{array}$ & @̊. & $\begin{array}{l}\stackrel{\circ}{\sim} \\
\stackrel{\sim}{ }\end{array}$ & $\begin{array}{c}0 \\
i \\
n\end{array}$ & in & 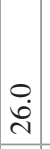 & $\begin{array}{l}0 \\
\stackrel{i}{\oplus} \\
\end{array}$ & 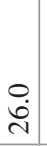 & $\begin{array}{l}i \stackrel{n}{n} \\
\ddot{n}\end{array}$ & & & \\
\hline 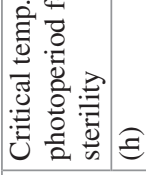 & & 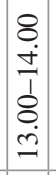 & & 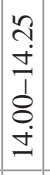 & 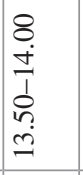 & & $\begin{array}{l} \\
8 \\
\stackrel{+}{+} \\
\wedge\end{array}$ & $\begin{array}{l}8 \\
\dot{1} \\
1 \\
1 \\
2 \\
\dot{2} \\
\end{array}$ & $\begin{array}{l}0 \\
m \\
m \\
0 \\
0 \\
0 \\
\ddot{m}\end{array}$ & & $\stackrel{n}{\simeq}$ & 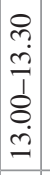 & 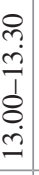 & & 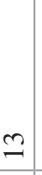 & 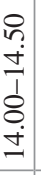 & & $\begin{array}{l}\stackrel{n}{r} \\
\stackrel{n}{\wedge}\end{array}$ \\
\hline 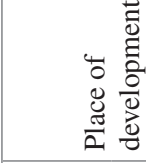 & & & 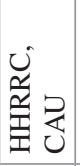 & 䘡 & $\sum_{1}^{2}$ & 慈 & 足 & $\begin{array}{l}\overline{8} \\
\stackrel{0}{Z} \\
\text { 至 }\end{array}$ & 产 & 竞 & 蛋 & 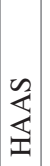 & 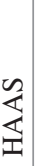 & & 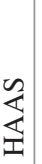 & 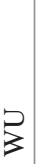 & & \\
\hline 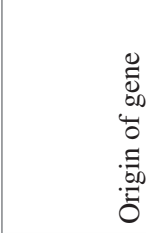 & & 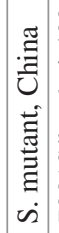 & 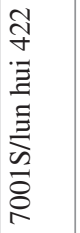 & 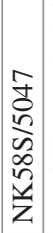 & 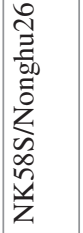 & $\begin{array}{l}n \\
0 \\
0 \\
1 \\
2 \\
\infty \\
0 \\
0 \\
0 \\
n\end{array}$ & 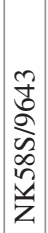 & 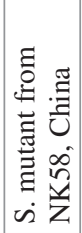 & 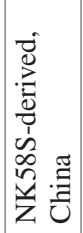 & & $\begin{array}{l}n \\
\infty \\
2 \\
2 \\
z\end{array}$ & & & & $\begin{array}{l}n \\
\infty \\
n \\
n \\
z\end{array}$ & 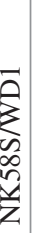 & & \\
\hline 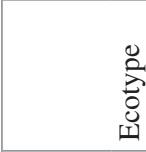 & : & 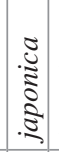 & 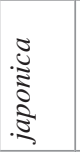 & 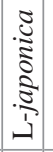 & 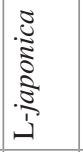 & 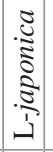 & 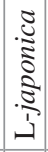 & 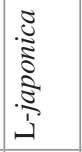 & 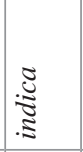 & 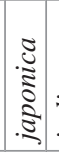 & : & 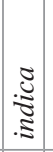 & 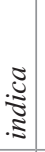 & & 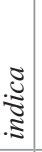 & 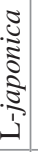 & 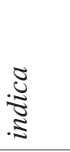 & 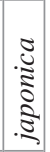 \\
\hline 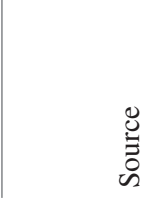 & $\frac{n}{2}$ & 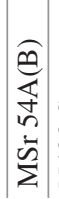 & $\begin{array}{l}\sim \\
\text { I } \\
\text { Z }\end{array}$ & \begin{tabular}{l}
$n$ \\
0 \\
\multirow{0}{0}{} \\
$n$ \\
$z$
\end{tabular} & $\begin{array}{l}n \\
\infty \\
\infty \\
\infty \\
0 \\
n \\
z\end{array}$ & $\begin{array}{l}n \\
0 \\
0 \\
0 \\
2 \\
z \\
z\end{array}$ & 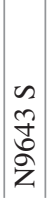 & $\begin{array}{l}2 \\
0 \\
0 \\
0 \\
0 \\
00 \\
0 \\
0 \\
z\end{array}$ & 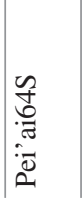 & 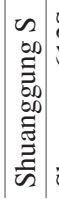 & 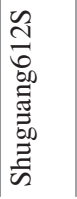 & $\begin{array}{l}n \\
5 \\
5 \\
0 \\
3\end{array}$ & $\begin{array}{l}n \\
n \\
\frac{n}{7} \\
\frac{3}{3}\end{array}$ & $\begin{array}{l}n \\
\tilde{0} \\
0 \\
a \\
3\end{array}$ & $\begin{array}{l}n \\
2 \\
2 \\
\hat{n}\end{array}$ & $\frac{n}{3}$ & 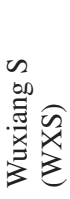 & $\begin{array}{l} \\
\infty \\
\infty \\
x\end{array}$ \\
\hline
\end{tabular}




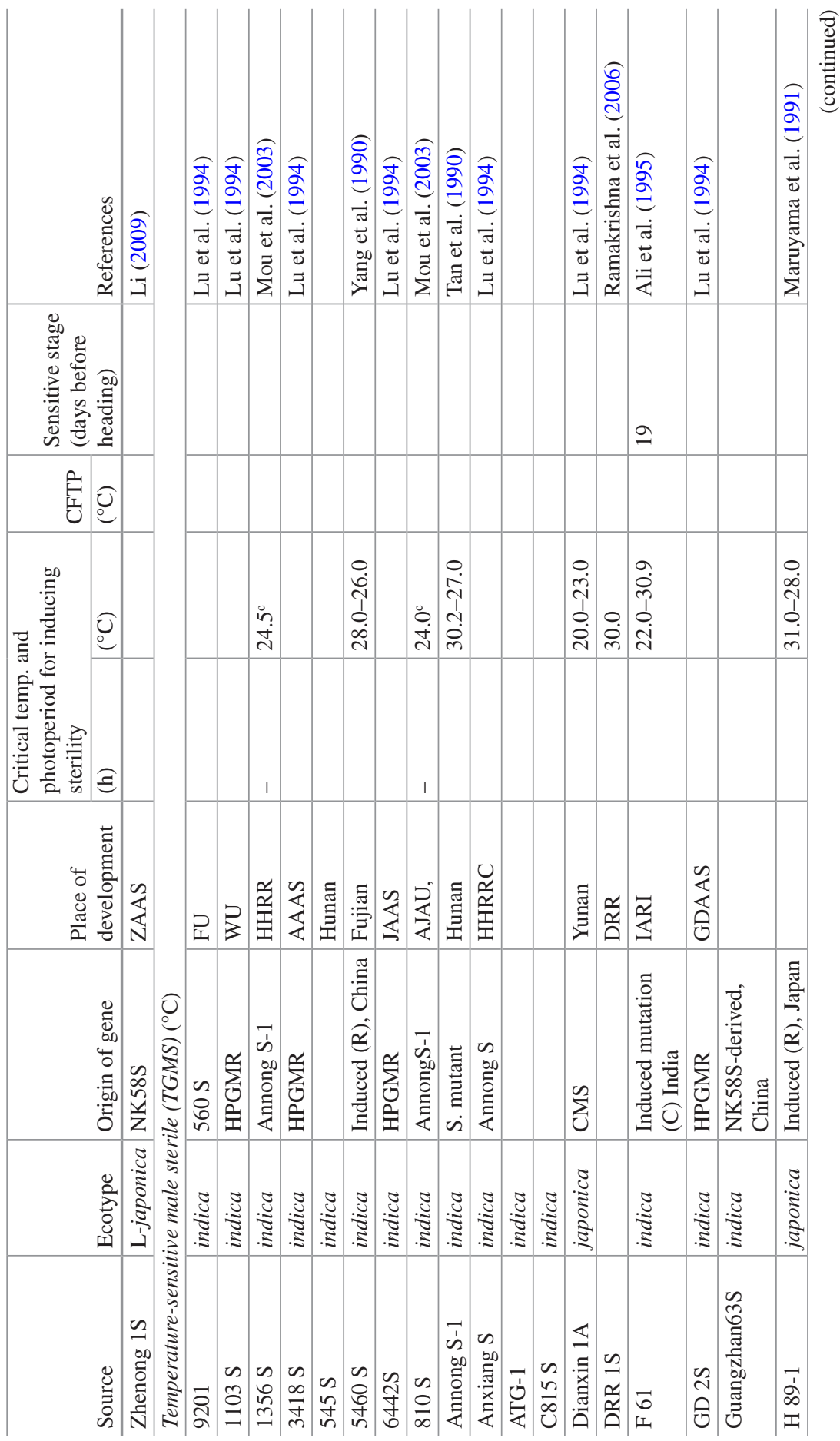




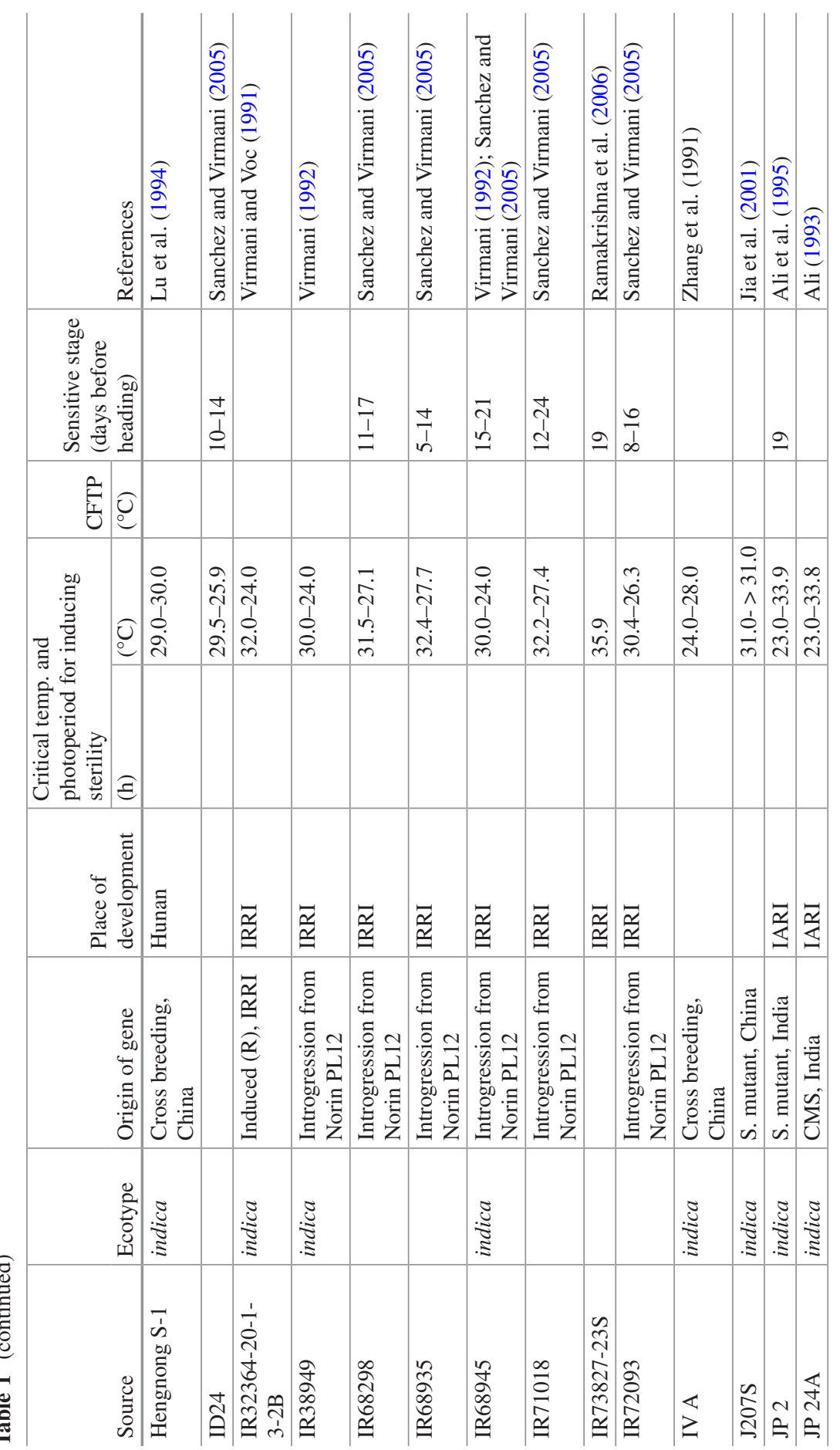




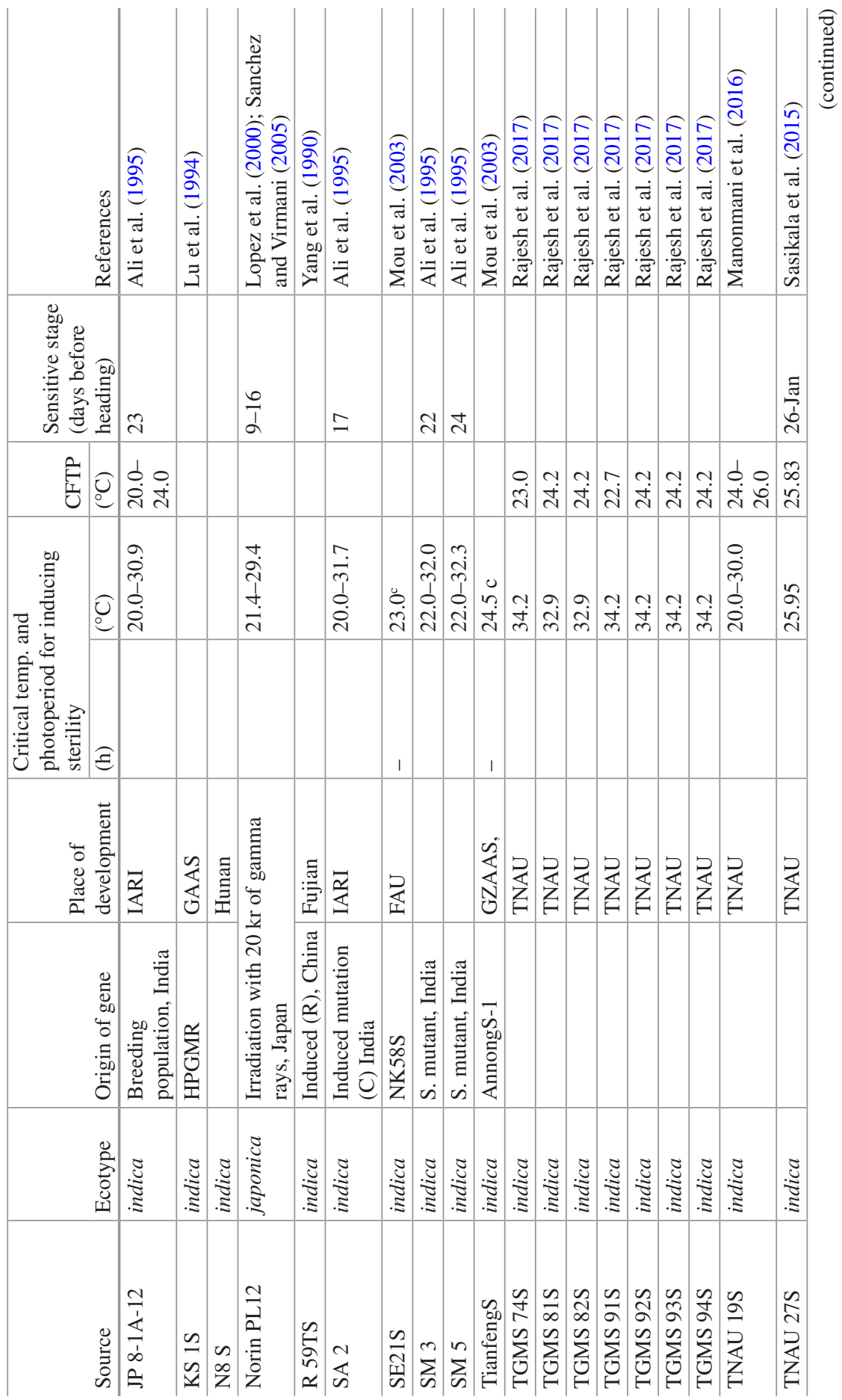




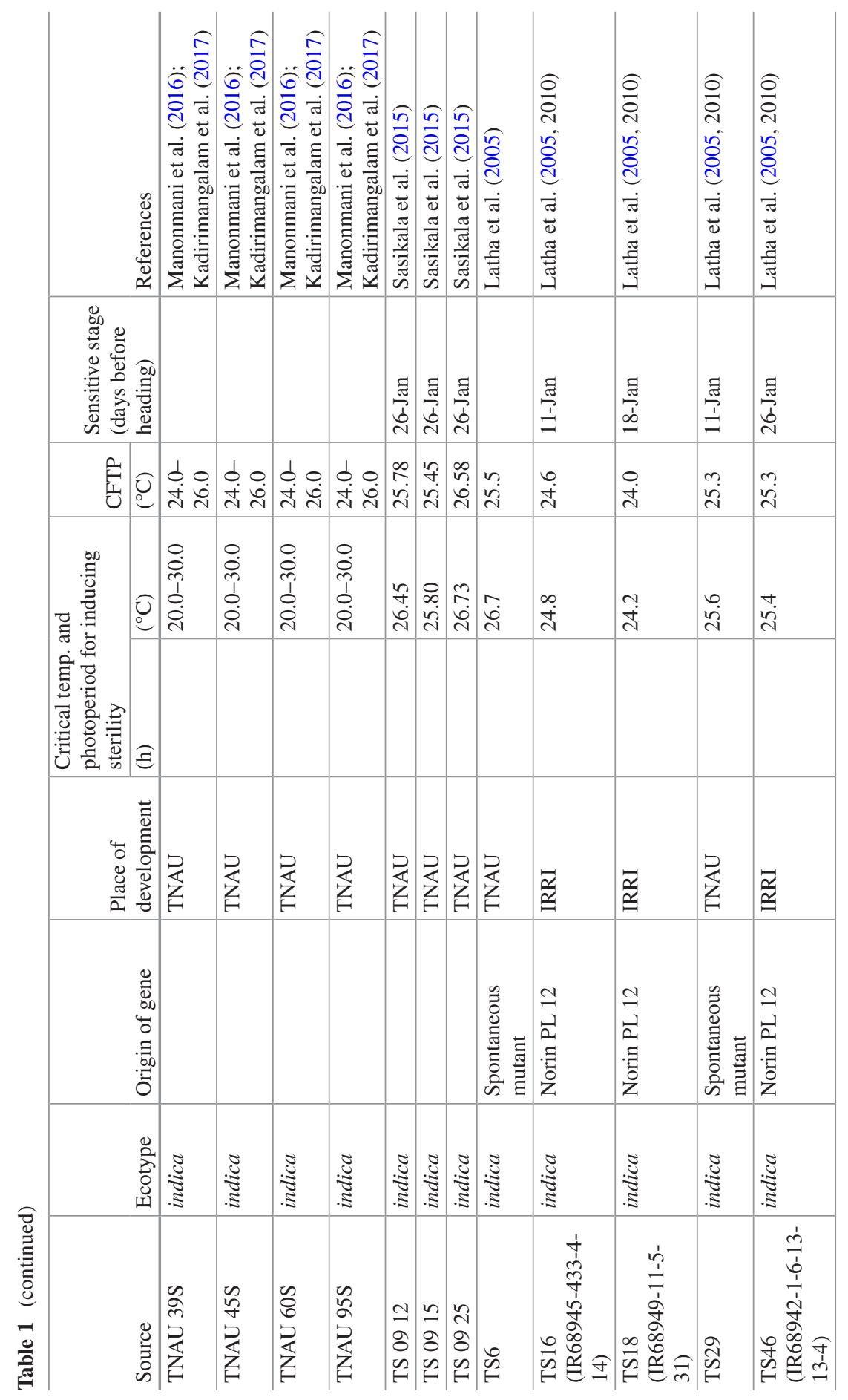




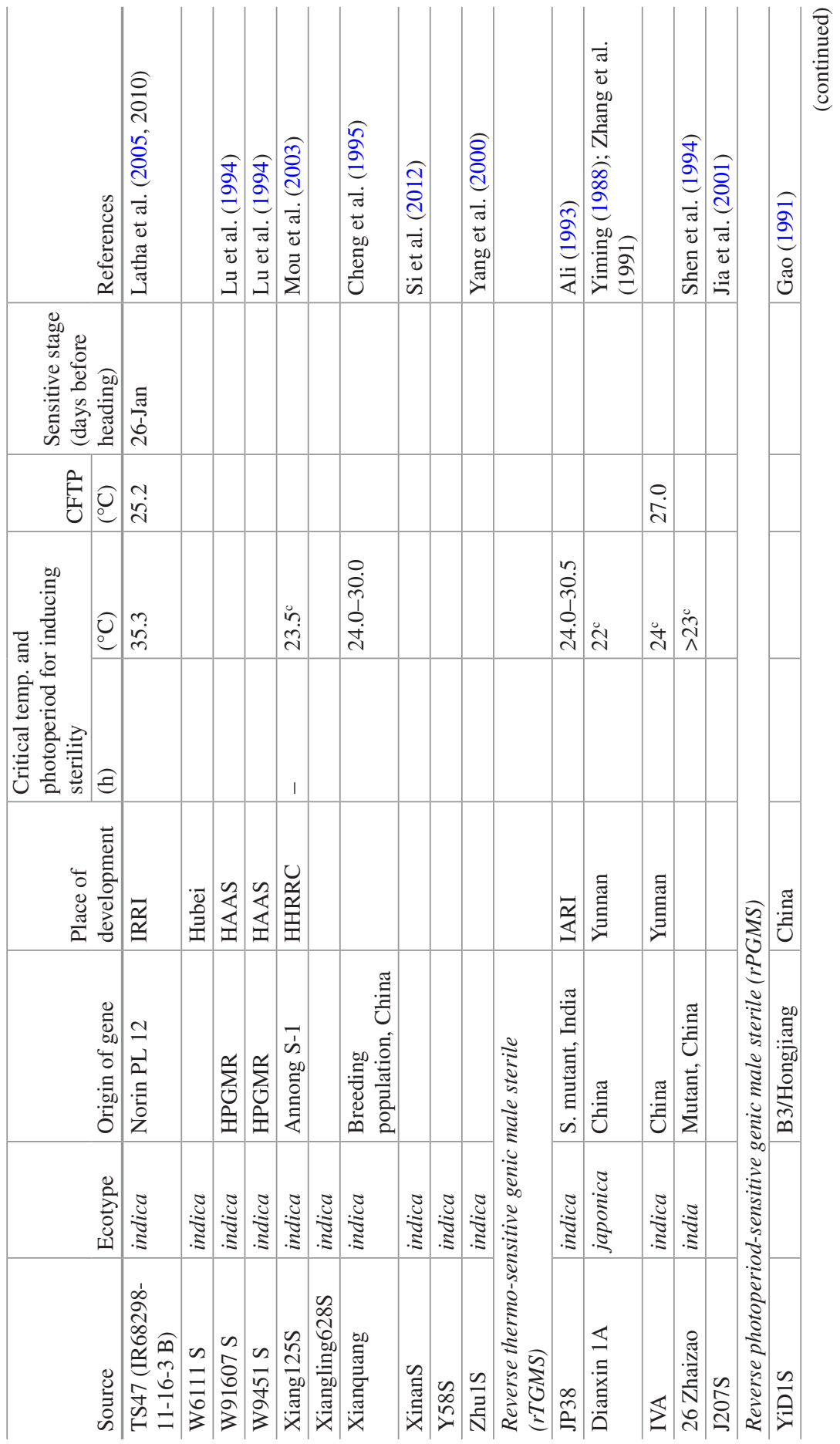




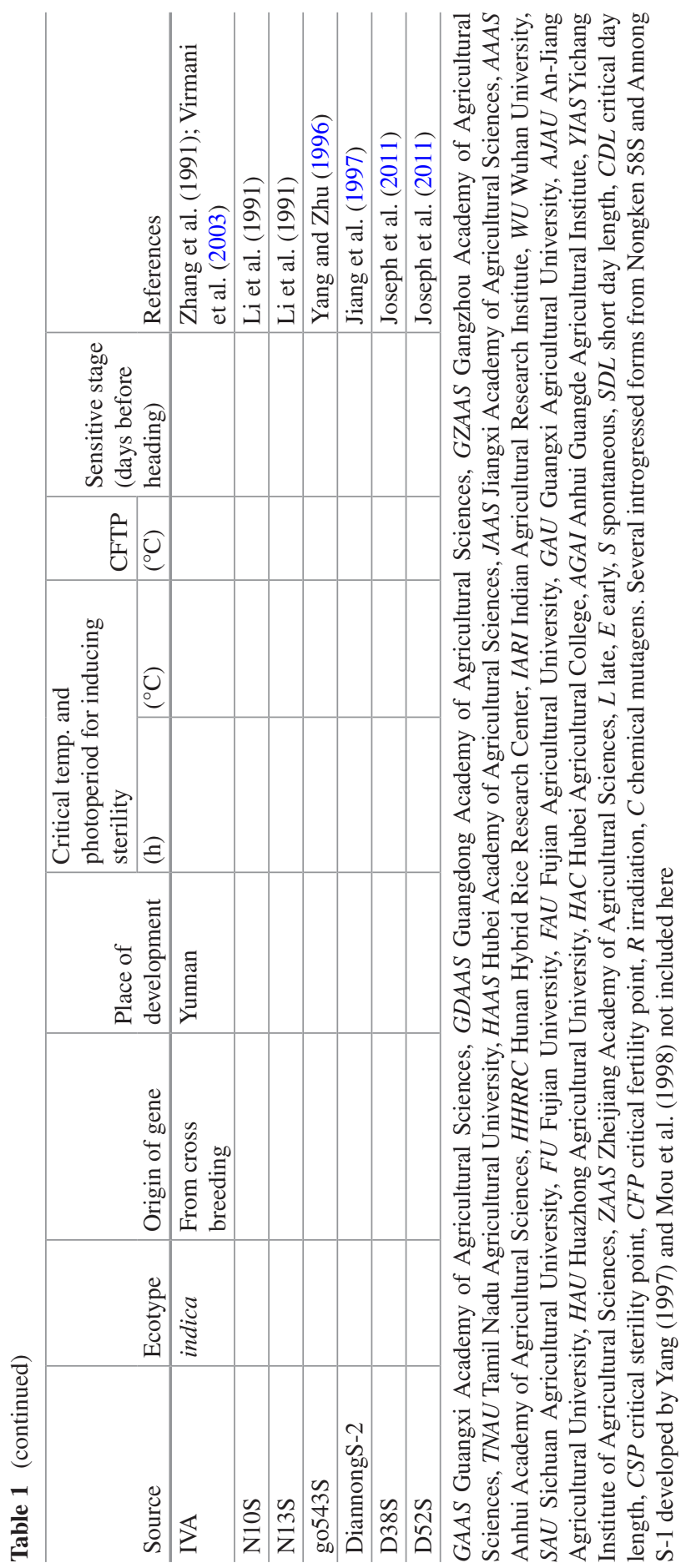


In this regard, to address tropical Asian markets, IRRI is refocused on developing two-line hybrid rice technology with usable TGMS parental lines. The two-line hybrid rice approach via TGMS holds great promise as it does away with one step of outcrossing of parental line production, thus directly bringing down seed costs. Although the two-line system is well established, especially in Vietnam and the Philippines, expansion to other regions remains a challenge because of the lack of TGMS lines with a low critical sterility temperature point (CSTP) of $24^{\circ} \mathrm{C}$. Such low CSTP of TGMS lines could be a game changer in tropical Asia vis-à-vis earlier discovered TGMS lines with CSTP of $>27^{\circ} \mathrm{C}$. Currently, the annual planting area of two-line hybrid rice in China has surpassed 5 million ha, while fully exploiting heterosis in rice (Chen et al. 2020). With recent research advances, TGMS-based two-line hybrid rice breeding is poised to replace three-line hybrid rice technology over the next decade (Ali et al. 2018).

\section{Advantages and Disadvantages of the TGMS System in the Tropics}

The TGMS-based two-line system has several advantages over the three-line system. First, hybrid seed production is less cumbersome as TGMS does not require maintainers and seed can be self-multiplied under fertility-conducive low-tempera-

TGMS system for two-line rice hybrids
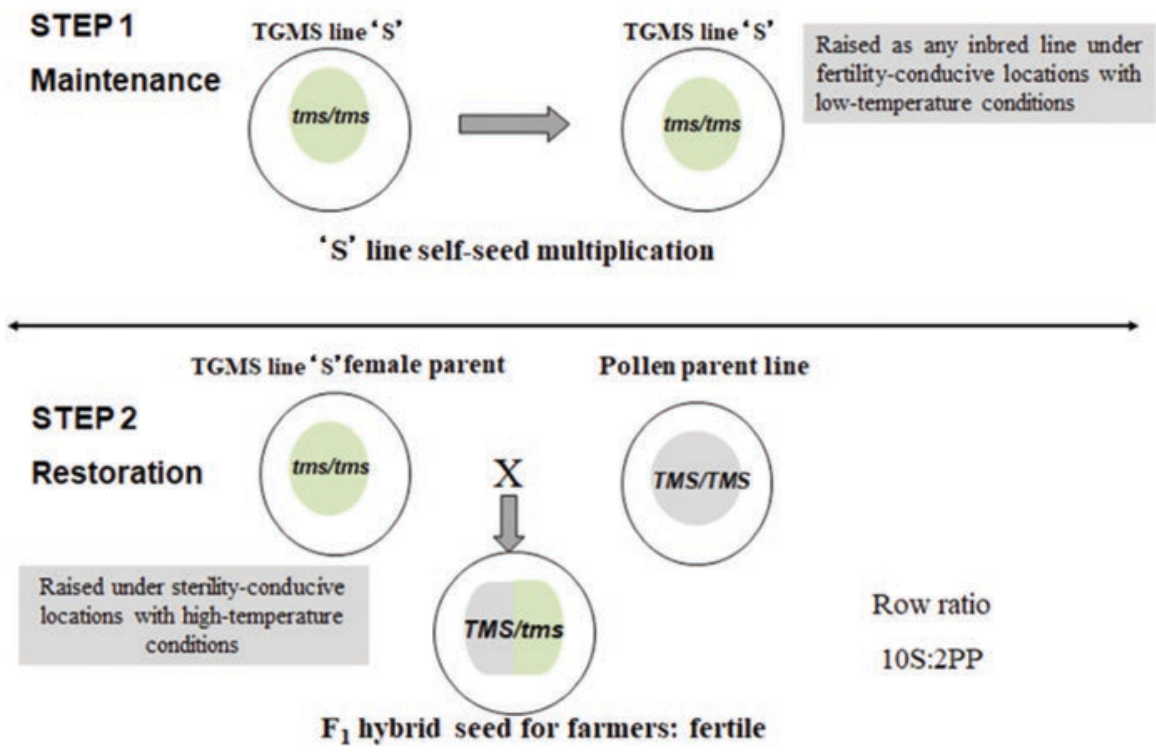

Fig. 1 TGMS system for the production of two-line rice hybrids 
ture conditions (Fig. 1). Second, there is a higher probability of identifying the heterotic pool and market-oriented hybrids, as any nonTGMS parent is a potential pollen parent. Third, the current CMS three-line system is primarily based on a single source of wild abortive (WA) cytoplasm that continues to pose a constant threat because of the adverse effects associated with it. However, the two-line approach also has certain shortcomings, such as the adverse effect of low-temperature fluctuations due to sudden/unforeseen weather changes that could trigger selfseeds in hybrid seed production plots. In addition, the higher temperature fluctuations in self-seed multiplication plots could result in lower self-seed yields of the TGMS lines. Therefore, the right choice of locations based on historical agrometeorological data is essential to identify ideal places for hybrid rice seed production and selfseed multiplication.

\section{Physiological Characterization of the TGMS Trait}

Homozygous and true-breeding TGMS lines need to be physiologically characterized, especially for CSTP and CFTP, besides determining the temperature-sensitive stage for sterility-fertility alteration. The deployment of TGMS lines needs to match the target location requirements. Furthermore, precise information on these two indices is essential for choosing an appropriate source for the development of twoline hybrids (Ali et al. 1995).

\subsection{Determination of CSTP and CFTP}

The determination of CSTP and CFTP is essential for characterizing TGMS lines for their proper exploitation in target regions. CSTP pertains to the lowest mean temperature among the temperatures inducing sterility, while the highest mean temperature causing fertility is considered as the CFTP (Chandirakala et al. 2008; Latha and Thiyagarajan 2010; Sasikala et al. 2015; Kadirimangalam et al. 2017). The tracking technique (Ali et al. 1995) was used to identify the CSTP and CFTP based on the sensitive stage of a line. Using this method, the CSTP is determined by obtaining the lowest among the maximum temperatures of the three tracking dates coinciding with the sensitive stage of the three panicles that caused complete pollen sterility. At the same time, the CFTP is the temperature range in which the plants produced a higher proportion of fertile and unaborted sterile (partially stained) pollen. Further studies by Vinodhini et al. (2019) considered the lowest value of the mean maximum temperature during the sensitive stage to determine the CSTP of a TGMS line. Viraktamath and Virmani (2001) proved that the maximum temperature is what influences the expression of fertility-sterility alteration of TGMS lines in tropical countries. Moreover, Kadirimangalam et al. (2017) identified TGMS lines with a CSTP at a mean temperature of above $29^{\circ} \mathrm{C}$. It is essential to understand that 
a given TGMS gene varies for its CSTP and CFTP when transferred to different genetic backgrounds (Sasikala et al. 2015). The fertility of PTGMS rice lines is affected by both temperature and light duration. Usually, PTGMS rice lines tend to produce low purity of hybrid seeds because of selfing at a low temperature $\left(23-24{ }^{\circ} \mathrm{C}\right)$ in seed production. The spikelets of PTGMS lines during anthesis could not normally open at high temperature $\left(\mathrm{HT}, \geq 35{ }^{\circ} \mathrm{C}\right)$, thereby severely decreasing hybrid seed yields (Chen et al. 2020). This, along with other factors, makes PTGMS unfavorable for use in tropical conditions. However, PTGMS materials may still be useful in temperate conditions where day length is more crucial.

\subsubsection{Characterization Under Controlled-Temperature Screening Conditions}

Sterile single-plant selections identified in a mutation population of the $\mathrm{M}_{2}$ generation or selections from segregating materials derived from TGMS $\times$ pollen parent (PP) crosses need to be stubbled and screened at low temperature to check for fertility reversion in the new emerging panicles. The crosses need to be bagged, and the generations correctly advanced under low-temperature facilities. At IRRI, the focus is on TGMS traits with low CSTP; thus, screening of the stable mutants and fixed materials is done under a phytotron in three mean temperature treatments $(23,24$, and $25{ }^{\circ} \mathrm{C}$ ) to determine their critical temperature for sterility/fertility induction (Fig. 2). This helped in identifying several TGMS lines with sterility at $24{ }^{\circ} \mathrm{C}$ and above and fertility at $23{ }^{\circ} \mathrm{C}$. A few sterile plants were also identified in all three temperature conditions and are currently being evaluated for fertility reversion at $<22{ }^{\circ} \mathrm{C}$. Wongpatsa et al. (2014) carried out a similar study using two TGMS lines (KU-TGMS1 and KU-TGMS3) screened at the panicle initiation stage under growth chambers using day/night temperature parameters of $26 / 22{ }^{\circ} \mathrm{C}, 26 / 20{ }^{\circ} \mathrm{C}, 24 / 18{ }^{\circ} \mathrm{C}$, and $22 / 20^{\circ} \mathrm{C}$, along with $11.5 \mathrm{~h} \mathrm{light} / 12.5 \mathrm{~h}$ dark periods and $75 \%$ relative humidity. Their results suggest that night temperatures of $18-22{ }^{\circ} \mathrm{C}$ induced maximum pollen viability and seed set. Furthermore, the highest seed rate was observed for KU-TGMS3 under $24 / 18{ }^{\circ} \mathrm{C}$, peaking at $33.63 \%$. In conclusion, this revealed that night temperature has a more significant effect on pollen viability than day temperature.

\subsubsection{Field Screening Through Sequential Seeding}

The physiological characterization of fixed TGMS lines can also be carried out through continuous seeding or sequential sowing. Sequential seeding is done in such a way that flowering is observed throughout the year at the candidate target sites to study pollen sterility and spikelet sterility (bagged and unbagged conditions). Such studies help in evaluating the stability of promising TGMS lines and determining the sterile phase window for hybrid rice seed production. Based on the tracking method (Ali et al. 1995), one can determine the CSTP and the sensitive 


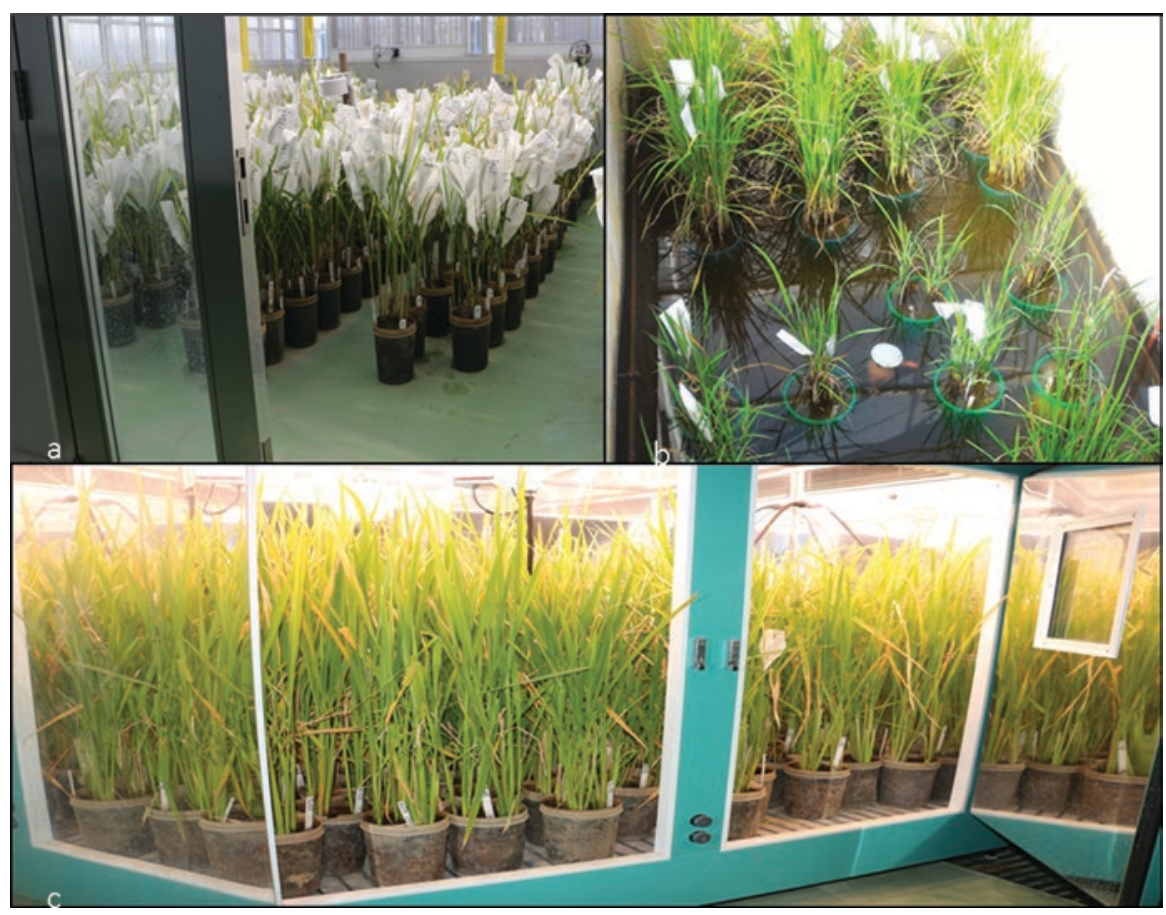

Fig. 2 Physiological characterization of TGMS lines in (a) plant growth facility bay, (b) coldwater facility, and (c) reach-in chamber

stage for sterility. A study done by Ramakrishna et al. (2006) observed six TGMS lines planted in three staggered sowing at intervals of 10 days. The lines were seen over two different seasons, postrainy 2002 (October-December) for fertility reversion with lower temperature range $\left(25.5 / 16.1^{\circ} \mathrm{C}\right.$ ) and prerainy 2003 (FebruaryApril) for sterility reversion with higher temperature range $\left(35.7 / 23.8^{\circ} \mathrm{C}\right)$, especially during the panicle initiation stage (Ramakrishna et al. 2006). Shuttle breeding of the selected sterile plants from segregating materials and their stubbles then transfers them to low-temperature conditions for obtaining self-seeds to advance the generations under low-temperature conditions. It would help to identify suitable TGMS lines for such environments. At IRRI, the sterile plant stubbles are sent to Lucban and Benguet in the Philippines for self-seed multiplication and generation advancement. Likewise, researchers at Tamil Nadu Agricultural University, India, evaluated TGMS lines in two sterility-inducing environments, Coimbatore and Sathiyamangalam, during rabi season starting in December 2013 and 2014. The same lines were stubble-planted and evaluated for pollen sterility in pollen fertilityinducing environments during kharif season in July 2013 and 2014 at the Hybrid Rice Evaluation Centre, Gudalur, a high altitude (1500 masl) with colder climate (Manonmani et al. 2016). Latha and Thiyagarajan (2010) also recommended a highaltitude area such as Gudalur for TGMS self-seed multiplication of lines such as 
TS29, which was observed to have only 16 days of fertile phase during December in Coimbatore. In Gudalur, TS29 had more than $60 \%$ pollen fertility and seed set when the mean temperature was $22^{\circ} \mathrm{C}\left(28 / 17^{\circ} \mathrm{C}\right)$ and below from June to November.

\subsection{Determination of the Critical Stage for Fertility-Sterility Alteration}

The critical stages of panicle development sensitive to temperature could be determined from the stages exhibiting a significant correlation with pollen sterility (Chandirakala et al. 2008). The stamen pistil primordial stage, which is 15-24 days before heading, was considered as the sensitive stage (Ali et al. 1995; Salgotra et al. 2012). Furthermore, Viraktamath and Virmani (2001) found 4-8 days after panicle initiation as the most sensitive stage. For the lines that Latha and Thiyagarajan (2010) had examined, those were sensitive to temperature from stamen pistil primordial differentiation to pollen ripening except for two lines that were sensitive from the meiotic division of the pollen mother cell to pollen ripening. The sensitive stages observed to vary with the four TGMS lines (TNAU 27S, TS 09 12, TS 0915 , and TS 09 25) showed a significant amount of positive correlation between pollen sterility and maximum and mean temperatures (Sasikala et al. 2015). The period of partial sterility was considered as the phase of fertility transition (Ali et al. 1995; Latha and Thiyagarajan 2010). Sanchez and Virmani (2005) observed differentiation of secondary branch primordium and the filling stage of pollen, that is, 24 to 5 days before heading was considered a sensitive stage for temperature. The results showed that the critical stage for most of the TGMS lines occurred during panicle developmental stages and approximately 26 to 5 days before heading (Kadirimangalam et al. 2017). Based on all these studies, we can demarcate the critical stage for sterility expression from 5 to 26 days before heading that coincides with the differentiation of secondary branch primordium and the filling stage of pollen. These sensitive days before heading also varied with early-, medium-, and lateduration TGMS lines and depending on the synchronous flowering habit.

\subsection{Evaluation of TGMS Lines for Sterility-Fertility Alteration in Different Environments}

TGMS-based two-line breeding programs require natural sites with low temperatures in higher altitudes in the tropics that are essential for advancing generations of selected TGMS lines. However, it will be worthwhile to select sterile plants with low CSTP in the range of $23-25^{\circ} \mathrm{C}$ as they are stable under high-temperature conditions $\left(28-30^{\circ} \mathrm{C}\right)$ for sterility. A recent discovery at IRRI of A07 with low CSTP of $24{ }^{\circ} \mathrm{C}$ is an excellent example of this type of TGMS line (Ali et al. 2018). Regular 
self-seed multiplication of TGMS lines is carried out for their use in hybrid rice seed production plots under high-temperature conditions. IRRI has two locations (Lucban and Benguet) for self-seed multiplication in the Philippines. Multilocation trials for two-line hybrid rice seed reproducibility trials are essential for understanding the stability of the TGMS parental lines and their outcrossing features.

\subsection{Improvement of Outcrossing Traits in TGMS and Pollen Parental Lines}

Outcrossing is directly correlated as a function of floral morphology and flowering behavior for the male-sterile parental line (Oka and Morishima 1967). The wider angle of lemma and palea correlated with greater exsertion and surface area of the stigma, leading to higher seed-set percentage. Visual phenotypic selection can be used efficiently to identify higher seed-set potential (Ramakrishna et al. 2006; Salgotra et al. 2012). According to the standards set by Chen et al. (2010), female parents should possess a panicle exsertion rate of $>70 \%$, along with an excellent outcrossing rate, early and short flowering span, and well-closed lodicules and lemmas after pollination. On the other hand, pollen parents should exhibit large anthers and pollen quantity, pollen vigor, and vigorous growth ability (Chen et al. 2010).

Better panicle exsertion from the sheath in male-sterile lines would help increase the number of spikelets for outcrossing than lines with incomplete panicle exsertion (Rahul Roy and Kumaresan 2019; Abeysekera et al. 2003; Virmani 1994). The lines with higher panicle exsertion percentage coupled with higher seed set and higher spikelet fertility percentage influence outcrossing ability and could be well exploited for the development of hybrid rice (Arasakesary et al. 2015).

Many of the traits for outcrossing in CMS, such as greater glume opening angle and more stigma exsertion, lead to higher seed setting (Mahalingam et al. 2013), which could be used as well for TGMS breeding. Outcrossing of relevant traits, especially the longer feathery stigma protrusion on either side of the lemma-palea and full glume opening, is highly attractive for increased pollination reception, germination, and seed set. Developing synchronous flowering habits in TGMS lines is essential for successful seed production. At IRRI, a few long feathery stigma-protruding types of TGMS lines with synchronous flowering patterns were successfully identified (Fig. 3) (Ali et al. 2018). Similarly, at TNAU, the TGMS lines developed through pedigree breeding, mutation breeding, and identification of spontaneous mutants in the breeding material were addressing the market requirements for medium duration, better agronomic characteristics, and excellent floral traits and requirements such as high stigma exsertion, wider glume opening, and acceptable grain quality characteristics such as medium slender grain type, etc. (Manonmani et al. 2016). However, the outcrossing traits translating into higher hybrid seed yields need to be verified under hybrid seed production geographies. 
Fig. 3 Newly developed TGMS line with long feathery stigma

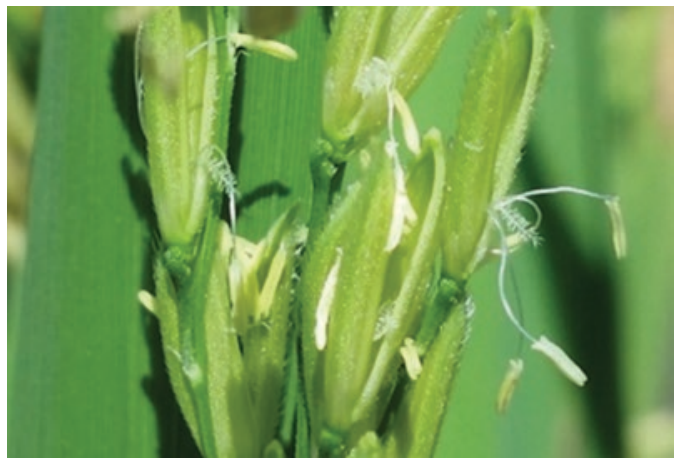

The floral traits of the pollen parents are also equally important to obtain higher seed setting. The pollen parents need to be highly diverse from the TGMS parental lines. At the same time, they need to possess floral traits similar to those of a restorer in the three-line system, especially in terms of plant height, profuse tillering, heavy pollen load, and pollen dehiscence. Moreover, the pollen parents should possess a staggered flowering habit to provide good pollen dehiscence during hybrid seed production. Consideration should be given to the synchrony of the timing of pollen dehiscence of pollen parents. It should match the TGMS parent's spikelet opening, and stigma receptivity is essential. In addition, pollen parents need to possess all the market-required traits such as appropriate grain shape and quality, abiotic stress tolerance, and insect pest and disease resistance.

\section{Genetics of TGMS Lines}

The recent discovery of new low-CSTP TGMS lines that showed complete sterility at a mean temperature of $24^{\circ} \mathrm{C}$ has sparked renewed interest in two-line hybrid rice technology. The genetics of the TGMS trait is essential for the exploitation of this technology.

\subsection{Identification of Genes Governing the TGMS Trait}

A single recessive nuclear gene governs the TGMS trait in TGMS lines (Hussain et al. 2012). So far, 13 TGMS genes and their alleles (tms 1 , tms2, tms 3, tms4, tms 5 , tms6, tms $6(t)$, tms 7 (t), tms 8, tms 9, tms 9-1, tms 10 , and tms $X$ ) found in 5460S, Norin PL 12, IR32364, SA 2, Annong S-1, SoKcho-MS, 0A15-1, UPRI-95-140TGMS, F61, Zhu1S, Hengnong S-1, japonica cv. 9522, and Xian S, respectively, have been identified based on their allelic relationship as well as molecular marker studies. (Wang et al. 1995; Subudhi et al. 1997; Yamaguchi et al. 1997; Reddy et al. 2000; 


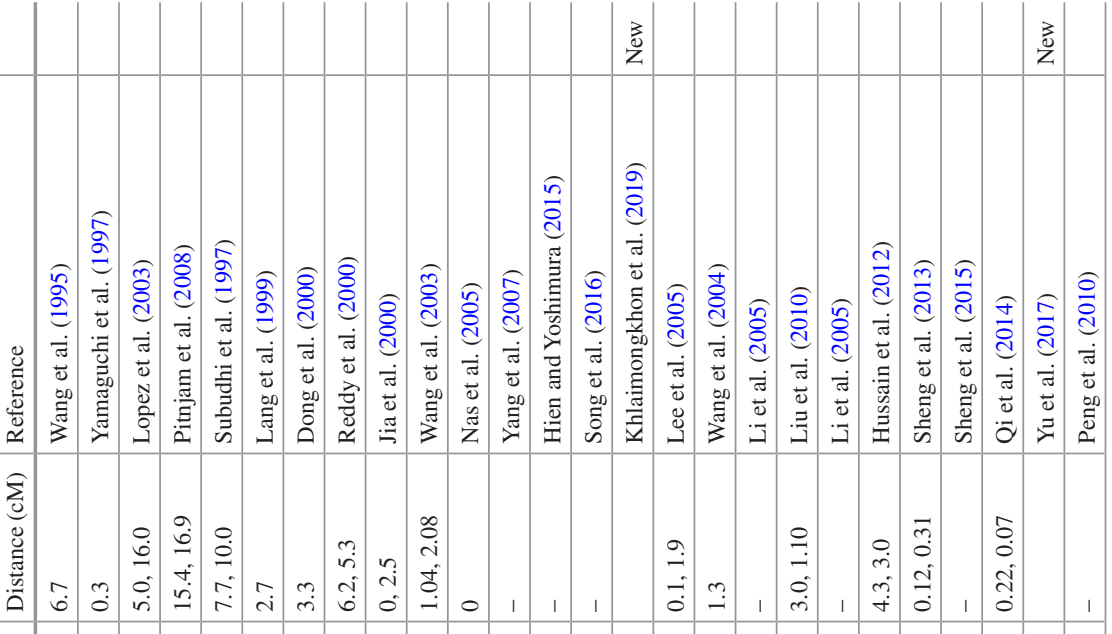

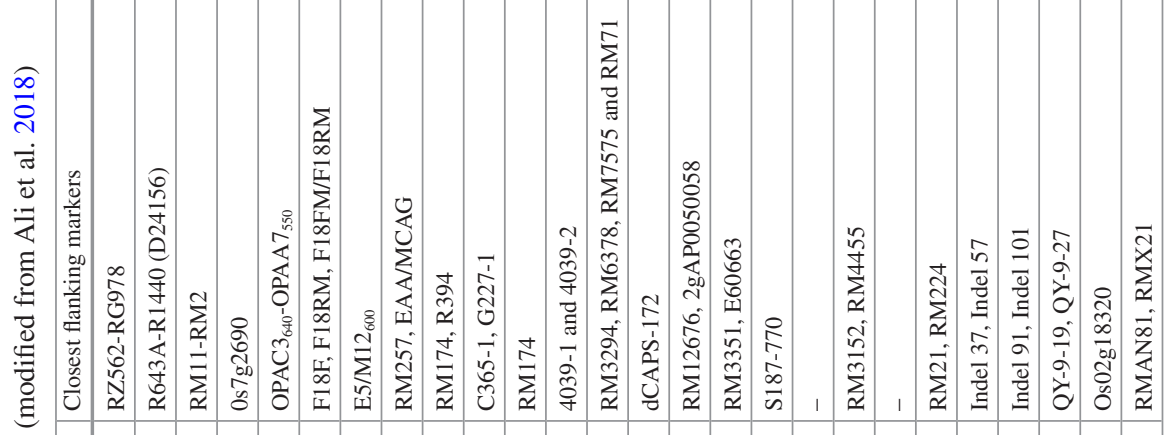
$\stackrel{\mathscr{0}}{*}$ $\Xi$

峁

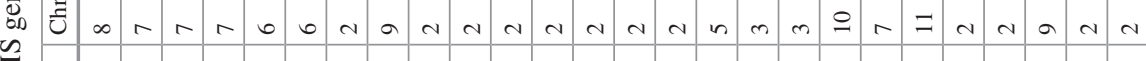

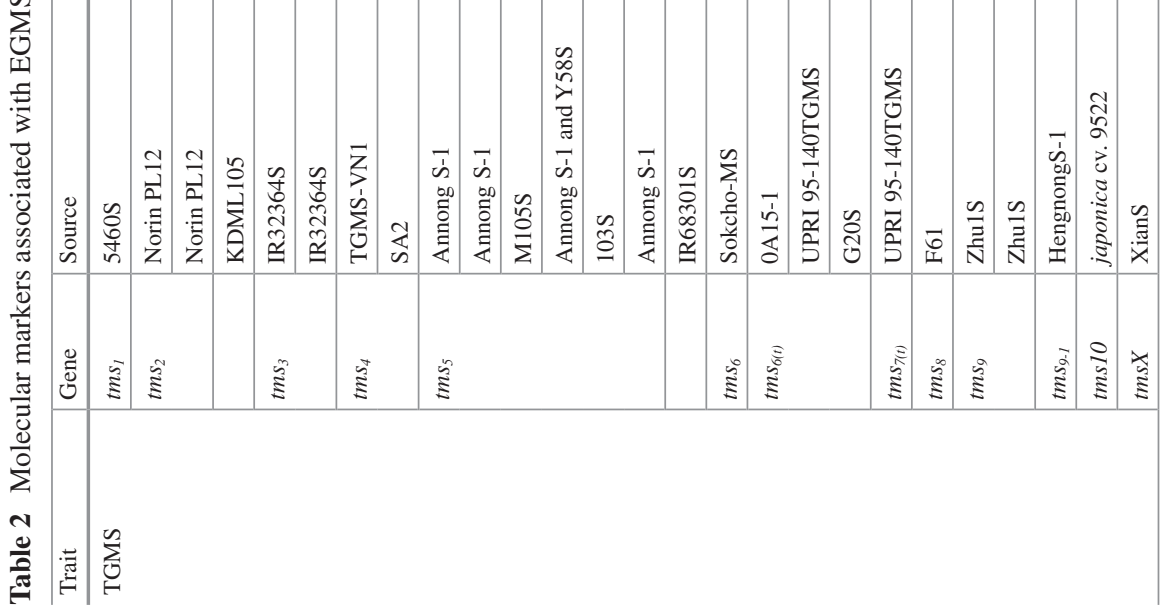




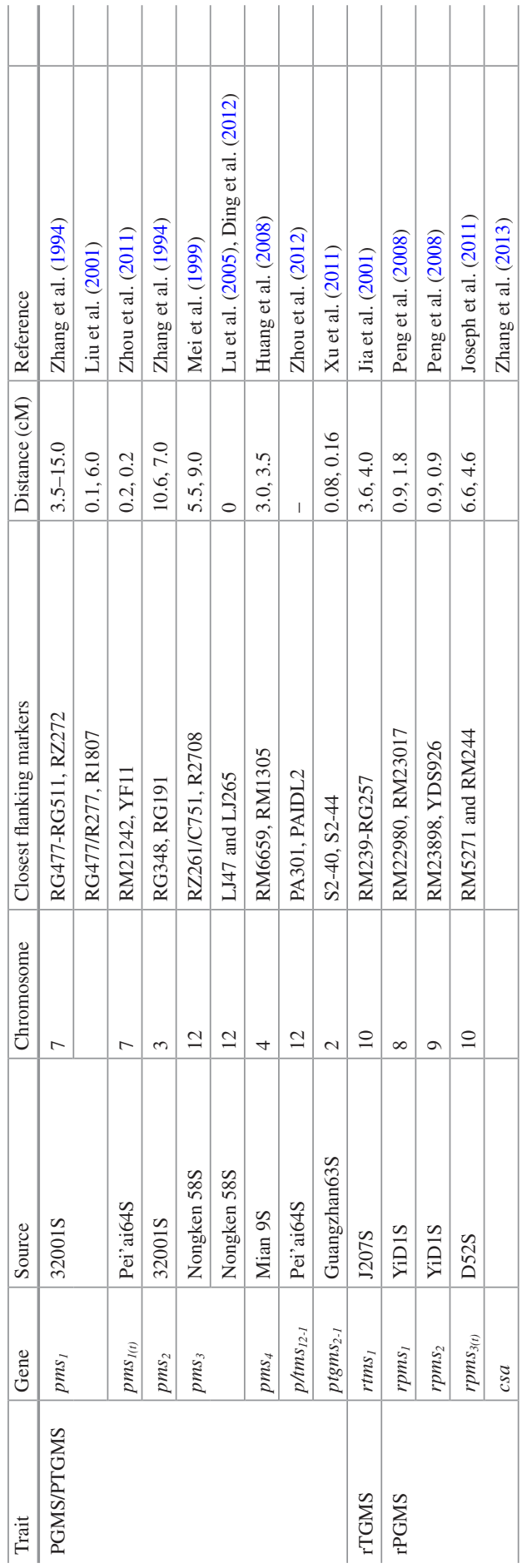


Jia et al. 2000; Wang et al. 2004; Lee et al. 2005; Li et al. 2005; Peng et al. 2010; Hussain et al. 2012; Sheng et al. 2013; Qi et al. 2014; Yu et al. 2017) (Table 2).

The identified tms genes could be further exploited for developing TGMS pyramiding lines by using two to three tms genes for improving stability during the sterility phase. However, only a few studies have been attempted on the pyramiding of these alleles, studying them for improving the stability of the TGMS lines (Nas et al. 2005). So far, $13 \mathrm{tms}$, seven pms, and three rtms genes have been identified governing the EGMS trait that is spread across all 12 rice chromosomes.

The TGMS trait is governed by a single major gene and could have several modifier genes that exist in different backgrounds. Therefore, it is crucial to characterize the TGMS lines physiologically before their commercial exploitation. The TGMS trait is much easier to transfer to other backgrounds through the marker-assisted backcross (MABC) approach, and one has to take care of modifier genes as well that may influence trait expression. In this context, it is essential to understand the molecular function of the TGMS trait (Ding et al. 2012; Zhou et al. 2012; Wang et al. 2013; Pan et al. 2014; Kim and Zhang 2017; Mishra and Bohra 2018).

Earlier studies on TGMS focused on the physiological aspects and how the gene is phenotypically expressed in the population. However, the first genetic study to confirm the location of the TGMS gene was begun by Wang et al. (1995) using an $\mathrm{F}_{2}$ cross from a mutant TGMS line (5460S) and Hong Wan 52. Bulk segregant analysis and QTL mapping using RAPD markers identified the first TGMS gene as TGMS1.2, located within chromosome 8 (Wang et al. 1995). Succeeding genetic studies are all compiled and given in Table 2 with the corresponding molecular markers.

\subsection{Molecular Mechanisms of the TGMS Trait}

With the advent of new technologies in the field of genomics and transcriptomics, Luo et al. (2020) confirmed the location of the tms gene, which was begun by Wang et al. (1995), for the identification of tms 1 on chromosome 8 using RFLP markers. This transition from RFLP to SSRs and more recently with transcriptomics in confirming the tms 1 loci led to the unraveling of the mechanism behind tms genes (Luo et al. 2020). Furthermore, Pan et al. (2014) showed that, in line TGMS-Co27, male sterility is based on the cosuppression of a UDP-glucose pyrophosphorylase gene (Ugp1), and the underlying molecular mechanisms need to be unraveled. Zhou et al. (2014) uncovered the molecular mechanism of rice tms 5 , which functions in RNase ZS1-mediated UbL40 mRNA regulation during pollen development. Under permissive (low) temperature conditions, the level of UbL40 mRNAs remains low in the tms 5 mutant plants, allowing the production of normal pollen. However, at restrictive (high) temperature, UbL40 mRNAs are not processed by RNase ZS1, which leads to their high-level accumulation, causing male sterility (Zhou et al. 2014). Wang et al. (2019) carried out a comparative quantitative proteomic analysis of the anthers of TGMS line Annong S-1 grown at permissive (low) $\left(21^{\circ} \mathrm{C}\right)$ and restrictive 


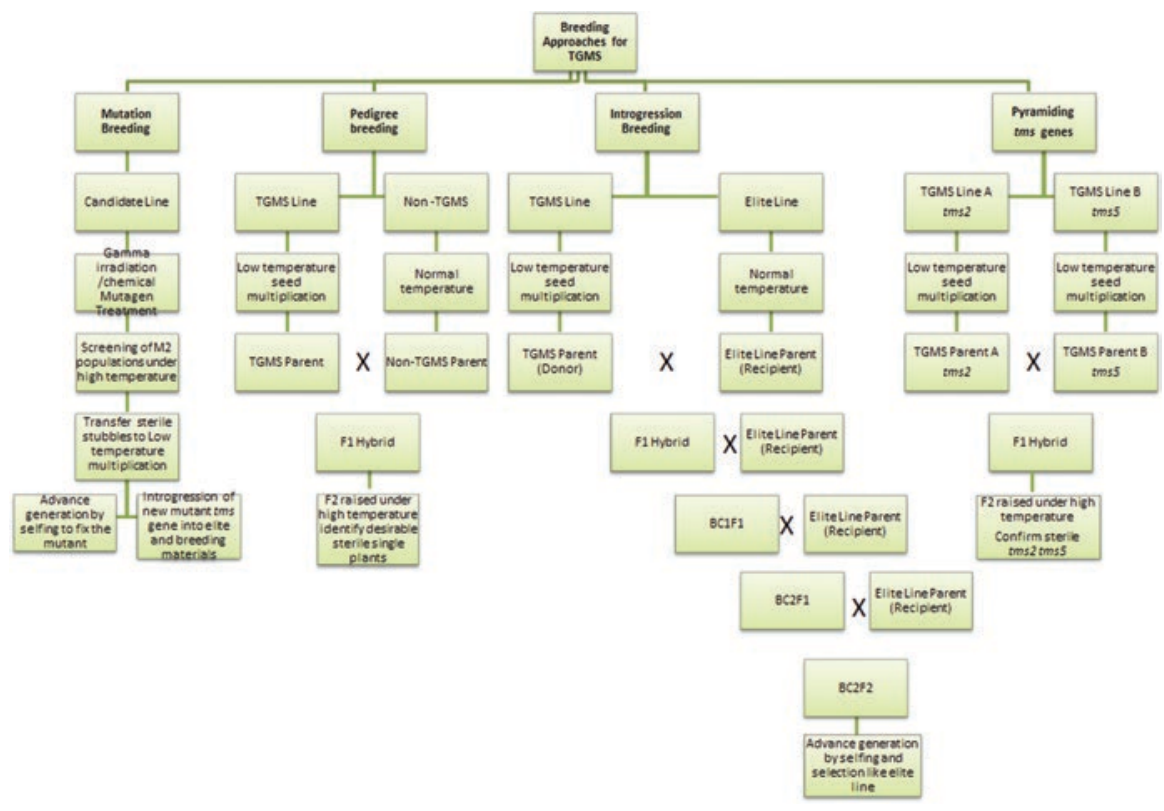

Fig. 4 Current breeding approaches for TGMS followed at IRRI

(high) temperatures $\left(>26^{\circ} \mathrm{C}\right)$. The restrictive high temperatures resulted in 89 differentially accumulated proteins (DAPs) in the anthers as compared to permissive low-temperature conditions. Out of the 89 DAPs, 46 had increased abundance and 43 had decreased abundance, which are distributed in most of the subcellular compartments of anther cells. Most have catalytic and binding molecular functions. Moreover, the gene ontology analysis for biological processes done by Wang et al. (2019) indicated that high-temperature induction caused the fertility-sterility conversion. This mainly adversely affects the metabolism of protein, carbohydrate, and energy and decreases the abundance of vital proteins closely related to defense and stress. This further impedes the growth and development of the pollen and weakens the overall defense and stress ability of Annong S-1.

Li et al. (2020) carried out RNA-Seq on rice TGMS lines at the microspore mother cell and meiosis stages under sterile and fertile conditions that revealed 1070 differentially expressed genes found to be enriched in protein folding, protein binding, regulation of transcription, transcription factor activity, and metabolicrelated processes. They showed that hub genes (such as UbL40s) were predicted to interact with proteolysis-related genes and DNA-directed RNA polymerase subunit, and heat shock proteins (HSPs) interacted with kinases to play significant roles in regulating fertility alteration. Their study suggested that, besides UbL40s, DNAdirected RNA polymerase subunit, kinases, and HSPs might be involved in TGMS fertility alteration and could be applied for TGMS breeding (Li et al. 2020). Despite several of these in-depth studies, the TGMS trait mechanism still needs to be unraveled entirely for its immediate exploitation by breeders. 


\section{Breeding of TGMS and Pollen Parental Lines}

Two-line breeding strategies for TGMS are currently carried out using four approaches: (a) the use of mutagenesis to induce new tms gene mutants from current materials, (b) conventional crossing and pedigree selection, (c) introgression of currently identified tms genes into elite lines, and (d) pyramiding known tms genes from different sources (Fig. 4). For each strategy, parental line selection remains the most crucial part to ensure hybrid vigor and address market segment requirements.

\subsection{Different Available Approaches to Breed TGMS Lines}

\subsubsection{Mutation Breeding for the Identification of TGMS Mutants}

Mutation breeding for the development of TGMS lines was first reported by Maruyama et al. (1991) for the development of Norin PL12 using gamma radiation. Furthermore, Ali et al. (1995) developed and characterized several TGMS lines using chemical and physical mutagens. Interestingly, Ali and Siddiq (1999) also identified a spontaneous mutant (JP38s) that showed a reverse TGMS trait, behaving as sterile at lower temperatures $\left(<24{ }^{\circ} \mathrm{C}\right)$ and as fertile at higher temperatures $\left(>30.5^{\circ} \mathrm{C}\right.$ ). IRRI began a mutation breeding program using chemical mutagens in 2015 to discover new TGMS mutants, which are currently being characterized. The mutation populations in the $\mathbf{M}_{2}$ generation need to be screened under high-temperature conditions to identify complete male sterility, and these are then stubbled and taken to low-temperature conditions to check for fertility reversions. Depending upon their seed settings in the stubbles, they are further generation advanced under low-temperature conditions to fix the TGMS mutants quickly. Upon fixation, these mutants are studied in different temperature regimes to characterize them physiologically (Ali et al. 1995, 2020 Unpublished).

\subsubsection{Pedigree Breeding}

It is also essential to breed new materials through crossing TGMS parents with elite lines and selection in the $\mathrm{F}_{2}$ generation for male-sterile single plants under hightemperature conditions. At IRRI, conventional crosses were made with the TGMS line A07 as a pollinator and elite breeding materials as the female parents (Ali et al. 2018). After the initial cross in the $F_{2}$ generation, the selected male-sterile single plants in high-temperature regimes are then stubbled and selfed seeds are produced under low-temperature conditions. These selected single plants are verified for the presence of the tms 5 gene across succeeding generations. Using this approach, a new TGMS line with the tms 5 gene will be developed (Ali et al. 2020 Unpublished). 


\subsubsection{Transfer from a Known TGMS Gene Source to Elite Lines}

Another strategy for integrating TGMS in two-line hybrid rice is by introgression of tms genes. At IRRI, the TGMS line A07 is used as a donor for introgressing the tms 5 gene into elite breeding materials by two backcrosses and selecting the progenies in $\mathrm{BC}_{2} \mathrm{~F}_{2}$ onward for the tms 5 gene. By using foreground markers and high-density background SNP markers, introgression of the tms 5 gene into elite materials is possible. However, it is essential to accurately characterize these materials upon fixation for their fertility-sterility alteration behavior.

\subsubsection{Pyramiding TGMS Genes for Better Stability}

Despite the independent successes in characterizing and isolating different TGMS genes in rice, only a few studies have dealt with the additive effect and pyramiding of different TGMS genes (Nas et al. 2005). Two- and three-gene pyramids constructed using the three TGMS donors, Norin PL 12 (tms2), SA2 (tgms), and DQ200047-21 (tms5), possessing the RM11 allele of Norin PL 12, RM257 allele of SA2, and RM174 allele of DQ200047-21 were selected. As expected, all selected progenies were male-sterile in sterility-inducing conditions (Nas et al. 2005). The pyramids developed from this effort were designated as IR80775-46 (with tms 2 and tms5) and IR80775-21 (with tms2, tgms, and tms5). Pyramiding tms genes is useful to improve the stability of the TGMS line and to widen the sterility phase. Currently, at IRRI, efforts are ongoing to pyramid tms 2 and tms 5 genes to understand the mechanisms of the genes and to improve the stability of the TGMS trait. The current

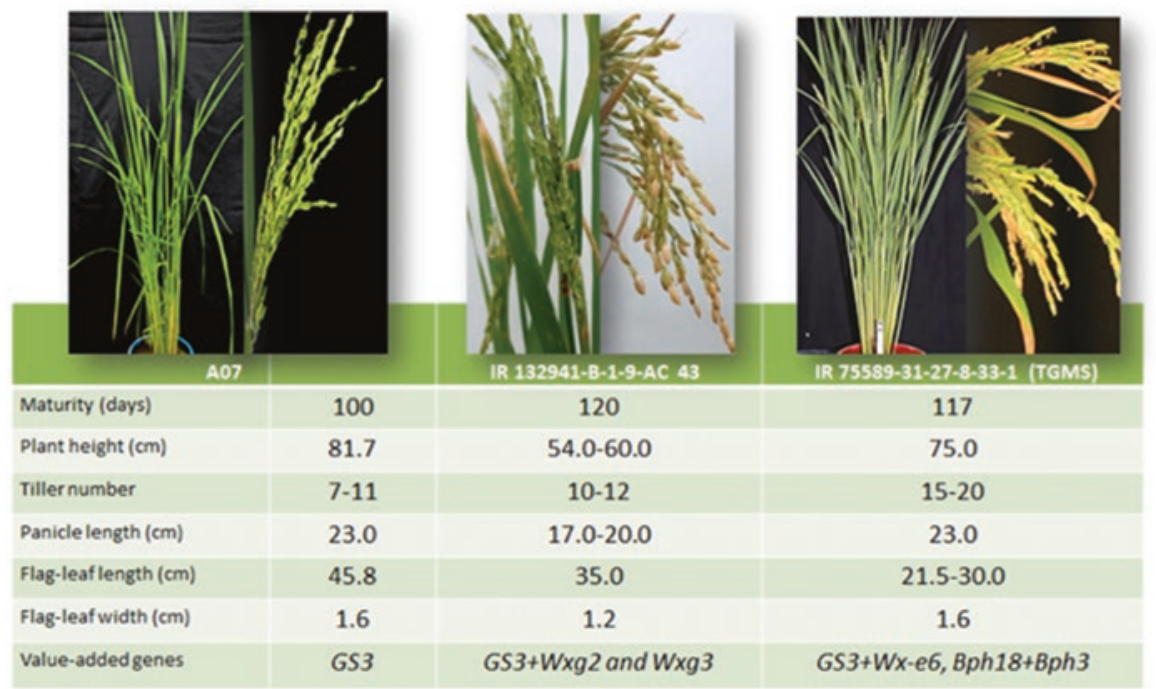

Fig. 5 New IRRI stable TGMS lines with low critical sterility temperature point at $24{ }^{\circ} \mathrm{C}$ 
Table 3 TGMS lines developed at IRRI (modified from Ali et al. 2018)

\begin{tabular}{l|l}
\hline S. no. & TGMS line \\
\hline 1 & A07 \\
\hline 2 & A32 \\
\hline 3 & A36 \\
\hline 4 & A37 \\
\hline 5 & IR75589-31-27-8-33-1 (TGMS) \\
\hline 6 & IR68301-11-6-4-4-3-6-6 (TGMS) \\
\hline 8 & IR73827-23-26-15-7 (TGMS) \\
\hline 9 & IR73834-21-26-15-25-4 (TGMS) \\
\hline 10 & IR75589-31-27-8-33 (TGMS) \\
\hline
\end{tabular}

\section{Sterility-fertility alteration in newly bred TGMS lines}
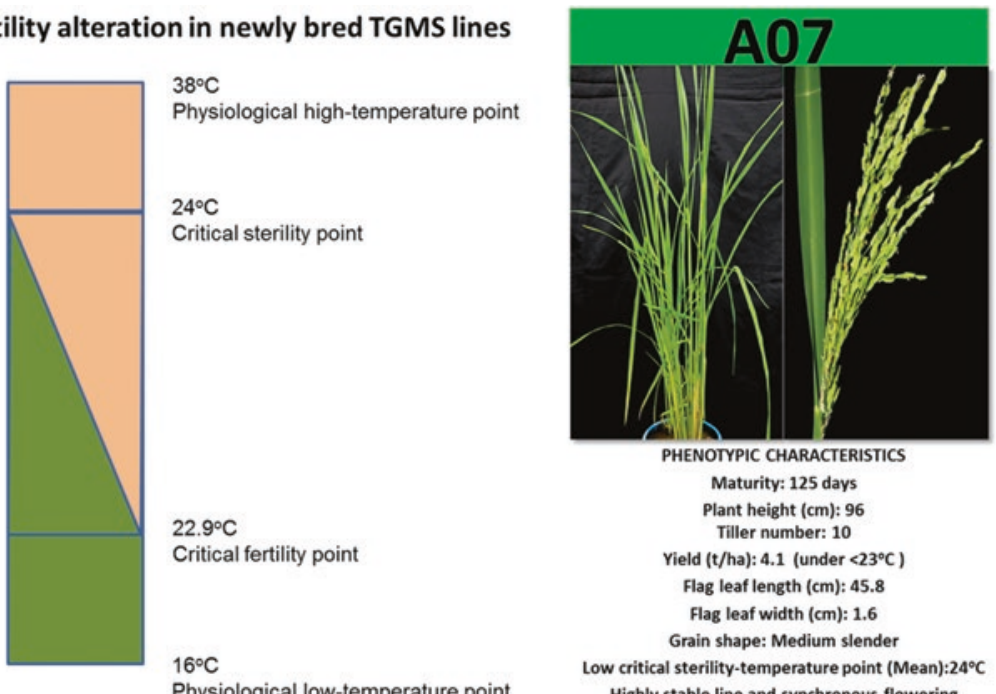

PHENOTYPIC CHARACTERISTICS

Maturity: 125 days

Plant height (cm): 96

Tiller number: 10

Yield ( $t /$ ha) $: 4.1$ (under $<23^{\circ} \mathrm{C}$ )

Flag leaf length $(\mathrm{cm}): 45.8$

Flag leaf width $(\mathrm{cm}): 1.6$

Grain shape: Medium slender

Low critical sterility-temperature point (Mean): $24^{\circ} \mathrm{C}$

Highly stable line and synchronous flowering

Fig. 6 New IRRI stable TGMS line with low critical sterility temperature point. (Source: Ali et al. 2018) 
TGMS pyramiding studies at IRRI used line A07 as a pollinator parent (Ali et al. 2020 Unpublished).

\subsection{Rapid Fixation of Segregating TGMS Lines}

Conventionally, generation advancement is accomplished by growing the plants under natural low-temperature locations, for example, Lucban-Quezon $\left(14.0805^{\circ} \mathrm{N}\right.$, $\left.121.5427^{\circ} \mathrm{E}\right)$ and Tublay-Benguet $\left(16.50805^{\circ} \mathrm{N}, 120.63524^{\circ} \mathrm{E}\right)$. This method remains the most popular as it is the most cost-efficient and requires the least technical work. This method, however, has its disadvantages as well. First, the environmental variables (temperature, humidity, and day length) at the location could cause genetic purities, mainly if fluctuations occurred during the plant's panicle initiation. Second, it requires labor-intensive cultural management of the field to prevent pests and diseases, especially under higher altitude locations in the tropics. Regardless of the fixation method, marker-assisted selection (MAS) is integral to the generation advancement of TGMS lines. MAS ensures the integrity of the tms gene and the genetic purity of the TGMS lines across generations.

Pedigree breeding and generation advancement of desirable TGMS segregants and mutants are challenging until the lines are correctly fixed. Recently, using new techniques of speed breeding under rapid generation advancement (RGA) facilities with specialized lighting, one can fix the segregating TGMS trait within 2-3 years, and this can be put to use to develop hybrid combinations. The use of the RGA method is a viable alternative to save on time and costs vis-à-vis field conditions. RGA hastens the fixation of new lines by advancing single seeds per line from a segregating population under controlled conditions (Collard et al. 2017). Instead of the usual dry and wet seasons, RGA allows several generations of advancement in a single season by growing the plants in trays instead of transplanting in the field to facilitate faster growth. Generations of TGMS breeding lines are advanced at low temperature $\left(<22{ }^{\circ} \mathrm{C}\right)$ in plant growth facility (PGF) chambers. It is essential to maintain the critical temperature and humidity necessary to induce pollen fertility and self-seed setting in plants, thus requiring more labor costs, a PGF, and technical expertise.

To speed up the fixation of TGMS traits in the mutants and segregants, one can use a doubled-haploid (DH) approach. It is essential to identify the right segregants and mutants for fixation through the DH approach (Fig. 5). Many times, the DH TGMS lines, once fixed, may not be the ideal ones to match the market requirements. IRRI has previously developed four TGMS lines using DH technology: A07, A36, A32, and A37 (Ali et al. 2018) (Table 3). Among them, A07 has already been validated as highly stable and it has a low CSTP of $24^{\circ} \mathrm{C}$ (Fig. 6).

Moreover, the tms gene present in this line (tms5) is the most extensively studied tms gene and it is used in different breeding programs as well (Wang et al. 2003; Nas et al. 2005; Yang et al. 2007; Kadirimangalam et al. 2019). Finally, DH technology offers the best potential among the three approaches. The use of DH technology 
ensures the fastest method of fixing recombinant genotypes, encompassing six generations of population advancement typically required to fix the population in just a single season (Yao et al. 2018). Moreover, the use of DHs eliminates the presence of deleterious alleles and background noise, which are typically observed in a natural population.

\subsection{Breeding Pollen Parents}

Heterotic pool-based breeding of pollen parents, more diverse and distinct from the TGMS pool, is required. These materials need to be improved within the pool and avoid contamination from materials nearer the TGMS heterotic pool. Breeders need to select for the target traits that help in pollen dehiscence, staggering flowering characteristics, and heavy tillering to provide a continuous pollen supply. Furthermore, the pollen parents need to address market segment needs so that the hybrids developed fit well. Pedigree breeding, single seed descent with genomic selection, along with RGA approaches could help to speed up the pollen parental breeding process. Specific traits such as genes with resistance against major insect pests and diseases that address market segment needs could be incorporated through a marker-assisted backcross (MABC) breeding approach.

\subsection{Two-Line indica/japonica Hybrids}

The two-line system is ideal for exploiting indica/japonica hybrids as there is no barrier for the identification of pollen parents, which could be any parent other than the TGMS parent. The TGMS gene could preferably be in the indica parental background, and with the use of a wide-compatibility (WC) gene in any one of the parents, one could develop indica/japonica hybrids. Shukla and Pandey (2008) suggested brighter prospects of combining improved japonica and tropical japonica germplasm having WC genes with indica TGMS lines for the exploitation of intersubspecific heterosis. Recently, with the discovery of reliable WC gene-based markers, ones such as $S 5$ could be highly useful for selection to combine with tms gene-based markers. At IRRI, the $S 5$ gene from different sources is backcrossed into TGMS line A07. Hybrid rice seed production of intersubspecific hybrids may be challenging due to the varying timing of spikelet opening and pollination of the two subspecies, especially in tropical environments. So, we need to carefully identify parental lines from these two subspecies closer to each other. 


\section{Breeding Two-Line Hybrids}

Two-line rice hybrids have higher heterosis than three-line rice hybrids as any nonTGMS line could be used as a pollen parent, thus creating more extensive opportunities. Unlike the three-line system, CMS requires only restorers with restorer fertility $(R f)$ genes to restore fertility in the $\mathrm{F}_{1}$ hybrid. Thus, it is a much narrower range within which heterosis needs to be exploited. On the other hand, TGMS-based two-line hybrids open up more opportunities to use the intersubspecific hybrids (indica/japonica) as the japonica subspecies has a low frequency of restorer genes. At IRRI, all source nurseries are genotyped, and heterotic pools are formed based on the genetic distances. Heterotic pool-based breeding is being followed to identify the best combinations for the two-line hybrids. To improve the heterotic pools, we have to make crosses within the pool. There is a need to maintain different heterotic pools carefully and to avoid contamination from other heterotic pools. To develop new heterotic hybrids, we can attempt crosses between distant pools.

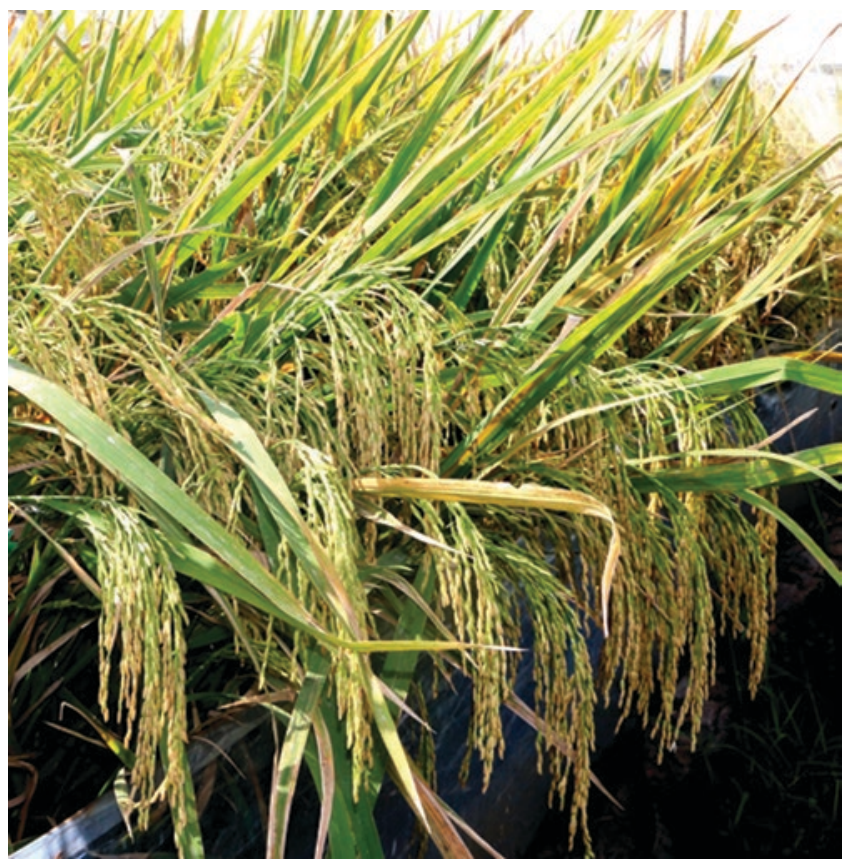

Fig. 7 IR134554H, a multiple-stress-tolerant two-line rice hybrid developed at IRRI 


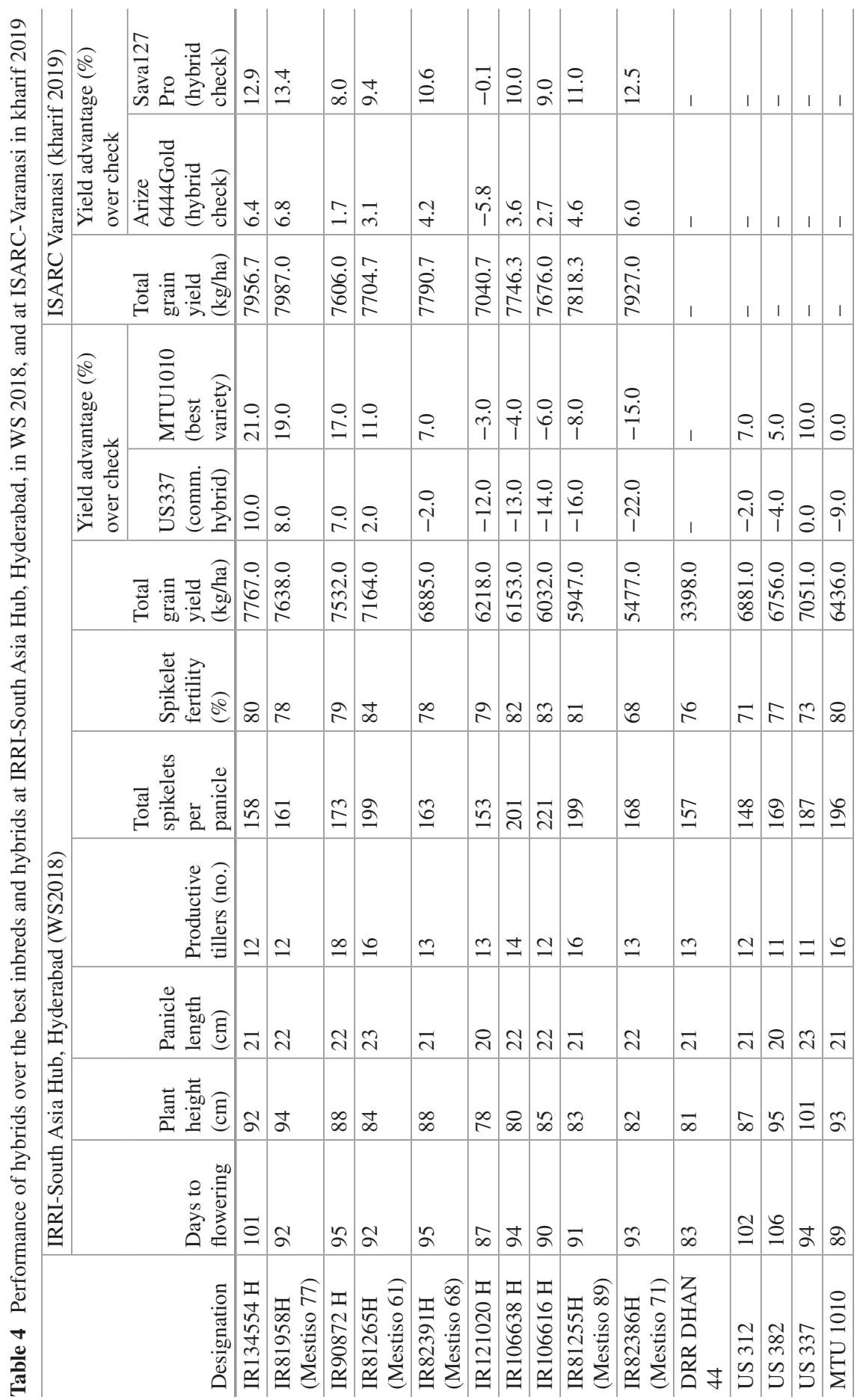




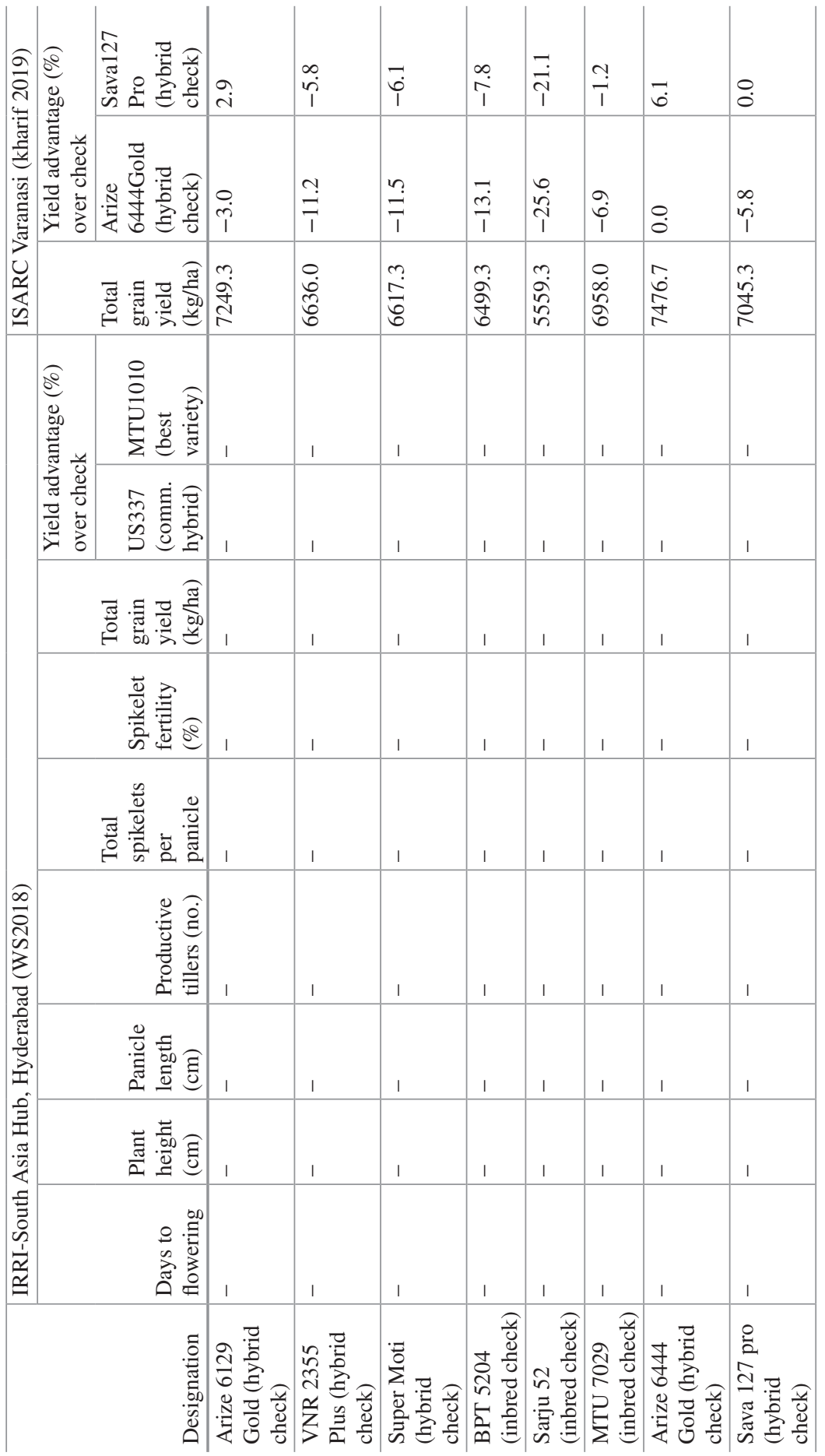




\subsection{Combining Ability Nurseries}

The general combining ability (GCA) of an inbred is its average performance across a series of hybrid combinations, and it is primarily due to the additive effects of genes. The GCA effects of the parental lines help in the identification of suitable parental lines (Chandirakala et al. 2012). The most promising TGMS lines developed in high combining ability backgrounds could be used to further identify and validate their general combining ability. For this, a line $\times$ tester design could be used to identify high GCA of lines. This also allows identifying combinations with high specific combining ability that could be immediately exploited. A combining ability nursery needs to be regularly created to identify TGMS lines with high GCA and pollen parents from the breeding pipelines. Chen et al. (2010) stressed the importance of identifying PTGMS with high combining ability as this is the basis of robust heterotic hybrid rice varieties. Cao and Zhao (2014) showed that successful hybrids are directly determined by the combining ability of the sterile line, and sterile lines with high GCA have higher chances to produce heterotic combinations. In situations with poor GCA of TGMS lines, it is good to have pollen parents with high GCA to develop heterotic hybrids. Shukla and Pandey (2008), with a broad set of line $\times$ tester crosses, found that the parents with good GCA did not always produce the best hybrid combinations due to a lack of higher-order additive interaction, and they suggested evaluating the specific combinations. They found TGMS line 365-8S to be the best general combiner for all six traits: grain yield, panicle length, grain number per panicle, earliness in flowering, panicle number per plant, and 1000-grain weight.

\subsection{Breeding Trials}

Once hybrid combinations are identified, small-scale seed production either by hand crosses or in field conditions should be sufficient to carry out an observation yield trial (OYT). An OYT evaluation of the $\mathrm{F}_{1} \mathrm{~s}$ under best management conditions would allow the identification of good performing hybrids, and these should be forwarded to an advanced yield trial (AYT) in a larger plot size with proper replications and the best market checks. Simultaneously, the AYT is screened for resistances to insect pests and diseases. The highly performing hybrids should be identified and sent for grain quality evaluation. Based on all the data, the best hybrids need to be produced in large quantities and also evaluated for their hybrid seed reproducibility for ensuring their success when screened in multienvironment trials (METs). The best candidate hybrids tested under METs lay the foundation for the identification of the best hybrids for a given target location and market segment. IRRI conducted two demonstration trials in India to evaluate the performance of some newly developed two-line hybrids. One hybrid (IR134554H) performed exceedingly well at both Hyderabad and Varanasi (Table 4, Fig. 7). 


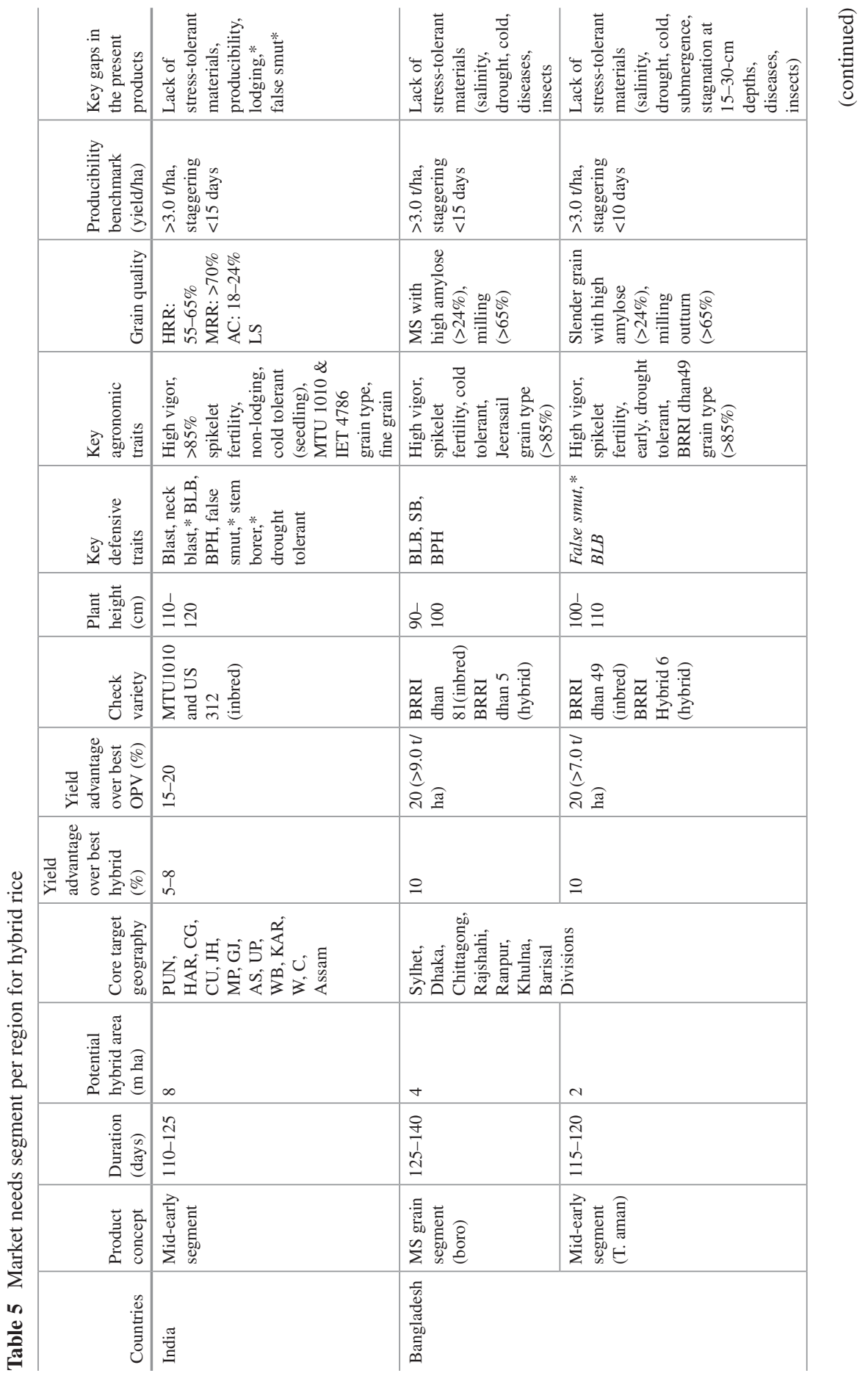




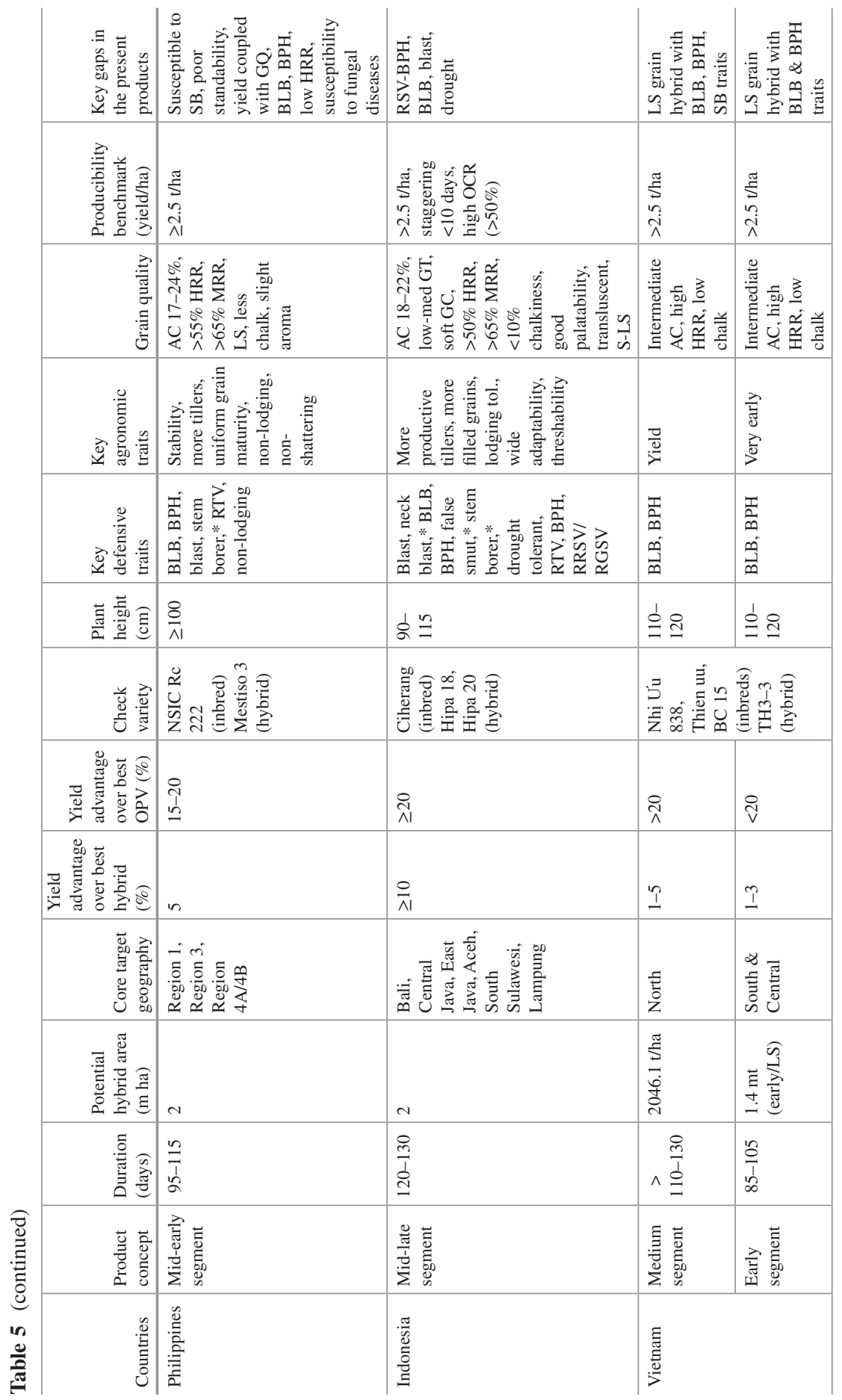




\subsection{Insect Pest and Disease Resistance}

Two-line rice hybrid yield potential could be fully realized by incorporating resistance to major diseases and insect pests (bacterial leaf blight (BLB), blast (BL), false smut (FS), sheath blight (SHB), tungro, green leafhopper (GLH), brown planthopper (BPH), stem borer, leaf folder, and gall midge). Most insect pest and disease resistances are governed by major genes and could be easily introgressed into parental lines depending on market segment requirements. Two-line breeding offers better opportunities to convert the TGMS parent to acquire disease and insect pest resistance as compared to a CMS/maintainer parent, which is more cumbersome and requires more time (Ali et al. 2018). In this regard, IRRI has developed a global product concept addressing different market needs, which could be useful, require fewer resources, and result in higher impact. Researchers at Huazhong Agricultural University (HAU) introgressed $\mathrm{Xa7}, \mathrm{Xa21}$, and $\mathrm{Xa23}$ genes into $\mathrm{C} 815 \mathrm{~S}$, a popular TGMS parental line, to develop five BLB-resistant cultivars: Hua1005S, Hua1002S, Hua 1009S, Hua 1006S, and Hua1001S (Jiang et al. 2015). Two-line hybrids with Xa23 showed a resistance reaction to seven Xanthomonas oryzae pv. oryzae (Xoo) strains. Hua1006S was the most promising TGMS parent among them with a higher degree of resistance based on $\mathrm{Xa} 33$ besides better plant type and grain quality features (Jiang et al. 2015). Currently, at IRRI, introgression of BLB and blast resistance genes into elite TGMS and pollen parental lines is carried out through marker-assisted selection.

\subsection{Grain Quality Considerations Addressing Market Needs}

A wider array of heterotic two-line rice hybrids opens up better options for developing customized grain quality that caters to market needs (Table 5). IRRI's two-line rice hybrid Mestiso 61 with good grain quality matched the market needs of the Philippines. It was successfully licensed to SL Agritech Company in the Philippines with limited exclusivity for a 6-year period. However, it is still available for license to the private seed industry for other countries under the Hybrid Rice Development Consortium. This hybrid gave an average yield of $6.7 \mathrm{t} /$ ha during the dry season and 6.4 t/ha during the wet season across the Philippines. The yield potential of this hybrid was nearly $10 \mathrm{t} / \mathrm{ha}$, with $55 \%$ head rice recovery and amylose content of $20.5 \%$, ideally fitting Philippine market needs. We developed a strategy to breed and customize grain quality as per market requirements (Allahgholipour et al. 2006; Pang et al. 2016). In this approach, breeders identify good-quality lines that will cater to the varied interests of consumers across rice-consuming countries by screening the breeding materials for eating and cooking quality (ECQ) and keeping the popularly preferred good-quality varieties as controls in the study. Furthermore, work is ongoing to identify advanced rice breeding lines/cultivars with similar apparent amylose content (AAC), gelatinization temperature (GT), and rapid vis- 
cosity analysis (RVA), properties like those of the popular high-quality rice varieties, through simple cluster analysis. A two-line hybrid from China, Pei-Liang-you 1108 , has relatively good ECQ, and through our study, we identified seven lines in the HC21 cluster clade with similar AAC, GT, and RVA and hence with comparable ECQ. Likewise, another two-line hybrid with good ECQ, Jin-ke-you651, allowed us to identify 11 hybrid lines within the HC18 cluster clade that had similar AAC, GT, and ECQ (Pang et al. 2016).

It is essential to develop rice hybrids with better ECQ that address market needs, paving the way for the expansion and adoption of rice hybrids in Asia and Africa. Higher hybrid rice yields have no value if they do not translate into higher percentage head rice recovery ( $>55 \%)$, leading to increased farmers' income.

\section{Seed Production Challenges}

Two-line hybrid rice technology largely depends on the identification of TGMS lines that need to be multiplied under low-temperature conditions, and hybrid rice seed production requires a minimum of 2 weeks of stable high temperature to reach the sterile phase. To achieve these two different aspects of seed production carefully, we have different approaches to identify appropriate locations based on agrometeorological data. However, this needs validation before large-scale seed production.

\section{Key Challenges}

- Addressing market requirements for different target places varies: for example, long-duration hybrids for the Indian market segment may require a longer duration of TGMS and pollen parents.

- Identification and exploitation of hybrid rice seed production and TGMS selfseed multiplication sites.

- Development of usable and stable TGMS parental lines matching market segment requirements.

- The relative heterosis of two-line rice hybrids needs to be superior to that of the existing best three-line hybrids in the market.

- Two-line hybrid rice technology should assure lower seed costs on account of better hybrid seed reproducibility rates of $3 \mathrm{t} / \mathrm{ha}$ and higher self-seed multiplication rates $(>4.5 \mathrm{t} / \mathrm{ha})$, making this seed feasible for use by farmers.

\subsection{Identification of Ideal Locations for Self-Seed Multiplication of TGMS and Hybrid Rice Seed Production}

TGMS-based two-line hybrid rice technology mainly depends on the identification of suitable areas for both self-seed multiplication and hybrid rice seed production (Table 6). Earlier, a systematic analysis of 50 years of agrometeorological data 
helped in the identification of appropriate sites in India (Siddiq and Ali 1999). Interestingly, the authors identified places located in India between 500 and $700 \mathrm{~m}$ above sea level from May to September for both hybrid seed and self-seed multiplication of the TGMS lines. Furthermore, through experimental validation, these places were confirmed as suitable for hybrid rice seed production, TGMS seed multiplication, and locations ideal for both operations (Siddiq and Ali 1999).

Critical considerations for the choice of place could be the hills, coastal plains, or interior plains, keeping within the physiological sterility limits of $<40{ }^{\circ} \mathrm{C}$ to $>16{ }^{\circ} \mathrm{C}$. The Two-line Hybrid Rice Research Station was established under Tamil Nadu Agricultural University in the Nilgiris hills at $1200 \mathrm{~m}$ above sea level in a place known as Gudalur as early as 1995 in India (Soundararaj et al. 2002). Malesterile TGMS selections at high temperatures at Trichy were made and immediately sent as stubbles to Gudalur to allow their self-seed multiplication and generation advancement. The most suitable time for matching the temperature conducive to self-fertility was from June to November. Shuttle breeding helped to identify 15 highly stable TGMS lines with better stigma exsertion of 40-66\%, and many are in the pipeline. Nearly 800 ha of paddy lands are available for commercial self-seed multiplication of promising TGMS lines (Soundararaj et al. 2002). In the Philippines, Lucban, Nueva Vizcaya, and Benguet are all identified as highly suitable for selfseed multiplication of TGMS lines. In Nueva Vizcaya, the mean temperature from the beginning of October to the end of February in the next year is less than $22^{\circ} \mathrm{C}$, making it a suitable place to reproduce TGMS line seed. The mean temperature at Lucban from January to February was $<23{ }^{\circ} \mathrm{C}$, and so all the TGMS lines possessing a CFTP of $<23{ }^{\circ} \mathrm{C}$ could be multiplied at Lucban. The TGMS lines should be completely male sterile to ensure the safety of hybrid seed production. Interestingly, we observed that the mean temperature at IRRI, Los Baños, was higher than $25{ }^{\circ} \mathrm{C}$ almost all year. So, the CSTP of fertility-sterility alteration of TGMS lines in the Philippines could be set at $>24{ }^{\circ} \mathrm{C}$ for ensuring completely safe hybrid seed production, especially from April to June.

Pollen of A07 was partially fertile to completely sterile at Lucban as observed from 5 May to 17 June and completely sterile (with no pollen type) at Los Baños. A07 possesses a lower CFTP to turn completely fertile at $<24{ }^{\circ} \mathrm{C}$. A07 seeds produced in Nueva Vizcaya are possible where lower temperature prevails as compared to Lucban (Ali et al. 2020 Unpublished). Recently, with GIS technologies, IRRI has successfully identified a suitable choice of sites for hybrid seed production and TGMS self-seed multiplication based on 20 years of agrometeorological data. The potential GIS maps for the Philippines, identifying the places suitable for self-seed multiplication and hybrid rice seed production, are shown in Fig. 8. A map with a $0.08^{\circ}$ spatial resolution and limited climatic data from 2010 to 2018 was used to avoid results affected by climate change trends. The following assumptions were used for locations selected based on temperature meeting a stable criterion for 28 days minimum each year, especially for hybrid seed production: (a) average daily temperature of $>28{ }^{\circ} \mathrm{C}$ and $\leq 36{ }^{\circ} \mathrm{C}$ and (b) a minimum temperature of $>24{ }^{\circ} \mathrm{C}$. Likewise, for TGMS self-seed multiplication, a criterion of average temperature of $<24{ }^{\circ} \mathrm{C}$ and $\mathrm{Tmin}>16{ }^{\circ} \mathrm{C}$ was used. 
Table 6 Ideal locations for two-line hybrid seed production and TGMS self-seed multiplication (modified from Ali et al. 2018)

\begin{tabular}{l|l}
\hline Seed production operation & Ideal places \\
\hline Hybrid seed production & $\begin{array}{l}\text { India: Aduthurai, Trichy, Killikulum, Madurai, Karnal, } \\
\text { Delhi Philippines: Los Banos }\end{array}$ \\
\hline TGMS seed production & $\begin{array}{l}\text { India: Aduthurai, Gudalur, Samalkota, Karnal; } \\
\text { Philippines: Lucban, Benguet, Nueva Vizcaya }\end{array}$ \\
$\begin{array}{l}\text { Hybrid seed production \& TGMS } \\
\text { seed multiplication }\end{array}$ & India: Aduthurai and Samalkota \\
\hline
\end{tabular}

\section{Wide-Scale Adoption and Use of Two-Line Hybrid Rice Technology}

To achieve wide-scale adoption of two-line hybrid rice technology, we need ideal TGMS lines that should possess a higher combining ability, outcrossing rate, and market-desirable grain quality features along with insect and disease resistance (Fig. 6). During the sterile induction phase, the plants must be $100 \%$ male sterile with more than $99.5 \%$ pollen sterility and must behave stably under well-defined fertility-sterility alteration conditions. Higher seed setting above $45 \%$ in the selfseed multiplication phase is essential. Ideal TGMS lines should have lower CSTP $\left(24^{\circ} \mathrm{C}\right)$ and lower CFTP $\left(22^{\circ} \mathrm{C}\right)$. However, researchers are still attempting to lower the CSTP to $23{ }^{\circ} \mathrm{C}$ (mean temperature), which will render the TGMS lines highly stable, especially during the sterile phase, and make them highly suitable for hybrid rice seed production. The frequency of heterotic hybrids is much higher for two-line hybrids than for three-line hybrids as any nonTGMS parent could be used as a pollen parent, thereby increasing hybrid breeding efficiency. Furthermore, as there is no need for restorer genes in the male parents of two-line hybrids, this is highly ideal for developing indica/japonica hybrids as most japonica lines do not possess restorer genes. Since there is no need for a maintainer line for seed multiplication, this makes seed production much simpler and highly cost-effective. Two-line hybrids have obvious superiority over three-line hybrids for rice grain yield, quality, and insect pest and disease resistance (Chen et al. 2010). In this regard, the best twoline hybrids should address market segment requirements with a 30-35\% yield advantage over market check inbreds and with higher seed reproducibility rates (>3 t/ha).

Two-line hybrid rice technology is feasible for tropical conditions for which the temperature regimes are highly suitable for its exploitation. TGMS parental lines with lower CSTP of $23{ }^{\circ} \mathrm{C}$ are highly essential for the success of this technology. At IRRI, we are trying to reach $22{ }^{\circ} \mathrm{C}$ for CSTP, which is even more stable and would ensure the wide-scale adoption of two-line hybrid rice technology. In this regard, the Two-Line Hybrid Rice Study Group involving key hybrid rice seed companies agreed to join hands in 2019 primarily to test-verify and validate potential TGMS lines, pollen parents, and $\mathrm{F}_{1}$ hybrids in the target geographies. The study group will be able to jointly confirm the strength of two-line hybrid rice technology, especially 


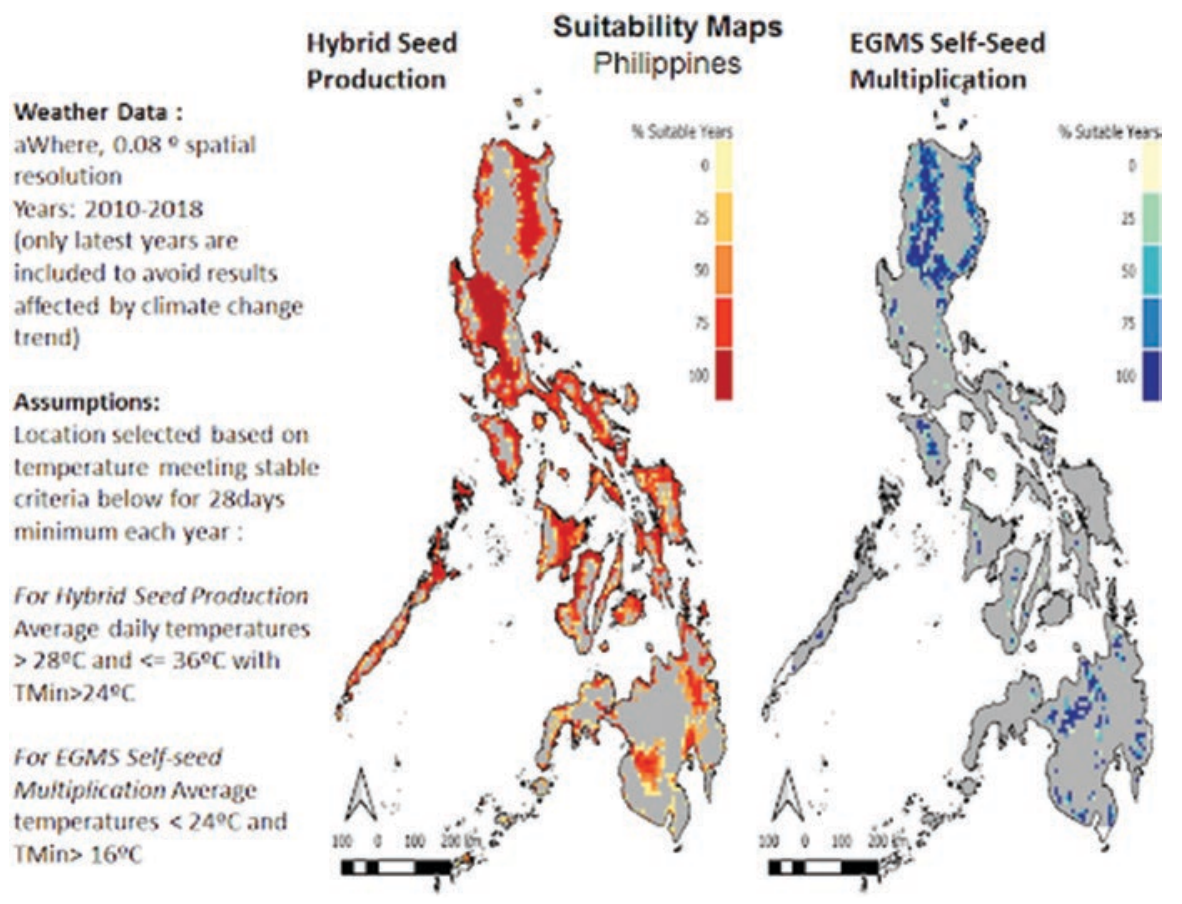

Fig. 8 Suitability maps for hybrid rice seed production and self-seed multiplication of TGMS lines for the Philippines developed by the IRRI GIS team

for its feasibility in South Asia. IRRI will continue to invest in this crucial technology for bringing the benefits of two-line rice hybrids to the rice farmers in South Asia. The accomplishment of this study group would ensure a lower cost of hybrid seeds, higher heterosis of two-line hybrids, and potential combinations meeting the market needs of the target regions. The success of two-line hybrid rice technology in tropical Asia would shift the attention of hybrid rice development in China toward South Asia, thus triggering widespread adoption of two-line rice hybrids.

\section{Future Directions and Conclusions}

The recent discovery of genome editing tools has opened up more opportunities to correct the genes of interest, including the tms gene, and to make them more stable and with precise expression. However, in many countries, genome editing is still under the genetically modified (GM) domain, including the Philippines. Li et al. (2019) introduced specific mutations into the TMS5, Pi21, and Xal3 genes in Pinzhan intermediate breeding material using the CRISPR/Cas 9 multiplex genome editing system. They demonstrated multiplex gene editing by finding transgene-free 
homozygous triple tms5/pi21/xal3 mutants obtained in the $\mathrm{T}_{1}$ generation that displayed characteristics of TGMS with improved resistance to rice blast and bacterial leaf blight. However, recent publications on editing the TMS5 gene and also achieving multiplex gene editing have increased our confidence to improve TGMS lines (Barman et al. 2019; Li et al. 2019; Zhou et al. 2016).

Wang and Deng (2018) described the development and implementation of the "third-generation" hybrid rice breeding system that is based on a transgenic approach to propagate and use stable recessive nuclear male-sterile lines. Using this approach, the male-sterile lines and hybrid rice produced using such a system are nontransgenic and hold great promise to boost the production of hybrid rice and other crops (Wang and Deng 2018).

To conclude, two-line hybrid rice technology primarily concentrates on the identification of proper TGMS parental lines with a lower CSTP $\left(23^{\circ} \mathrm{C}\right)$ and matching market segment requirements. The hybrids developed out of these TGMS parental lines should also meet market needs by achieving consumer and farmer acceptance that includes duration, grain shape, grain quality, and insect pest and disease resistance. Furthermore, these top-performing hybrids should have a high hybrid rice seed reproducibility of $>3$ t/ha to allow the private sector to adopt them. Also, hybrid rice seed costs would become relatively cheaper and enable farmers to invest in the purchase of seeds. Two-line rice hybrids have several advantages over three-line rice hybrids, and they could be easily upscaled once they match market needs. The Two-line Study Group was formed in 2019 at IRRI to understand the fundamental challenges for the wide-scale adoption of two-line hybrid rice technology and validate the research efforts by IRRI to meet these challenges and make the technology feasible. The study group is in the process of testing and verifying IRRI TGMS materials in the target regions. Recent advances in the field of GIS and the precise identification of suitable locations for hybrid rice seed production and TGMS selfseed multiplication, especially in the tropical countries in Asia and Africa, have given us the confidence to scale up two-line hybrid rice technology.

\section{References}

Abeysekera SW, Abeysiriwardana DS, Dehideniyz E (2003) Characteristics associated with outcrossing rate of cytoplasmic male sterile (CMS) lines in rice under local conditions. Ann Sri Lanka Dept Agric 5:1-6

Ali J (1993) Studies on temperature sensitive genic male sterility and chemical induced sterility towards development of two line hybrids in rice (Oryza sativa L.). Dissertation, Indian Agricultural Research Institute, New Delhi, India

Ali J, Siddiq E (1999) Isolation and characterization of a reverse temperature sensitive genic male sterile mutant in rice. Indian J Genet 59(4):423-428

Ali J, Siddiq E, Zaman FU, Abraham MJ, Ahmed IM (1995) Identification and characterization of temperature sensitive genic male sterile sources in rice (Oryza sativa L.). Indian J Genet 55(3):243-259

Ali J, Dela Paz M, Marfori CM, Nicolas KL (2018) Environment sensitive genic male sterility (EGMS) based hybrid breeding in rice. In: Rao PV, Muralidharan K, Siddiq EA (eds) Modern 
breeding strategies for crop improvement. Proceedings of one-day dialogue on 10 July 2017, Professor Jayashankar Telangana State Agricultural University (PJTSAU), Rajendranagar, Hyderabad, India, $\mathrm{p} 250$

Allahgholipour MA, Ali AJ, Alinia F, Nagamine T, Kojima Y (2006) Relationship between rice grain amylose and pasting properties for breeding better quality rice varieties. Plant Breed 125(4):357-362

Arasakesary SJ, Manonmani S, Pushpam R, Robin S (2015) New temperature sensitive genic male sterile lines with better out-crossing ability for production of two line hybrid rice. Rice Sci 22(1):49-52

Athwal DS, Virmani SS (1972) Cytoplasmic male sterility and hybrid breeding in rice. In: Rice breeding. International Rice Research Institute, Los Baños, pp 615-620

Barman HN, Sheng Z, Fiaz S, Zhong M, Wu Y, Cai Y, Wang W, Jiao G, Tang S, Wei X, Hu P (2019) Generation of a new thermo-sensitive genic male sterile rice line by targeted mutagenesis of TMS5 gene through CRISPR/Cas9 system. BMC Plant Biol 19(1):109. https://doi.org/10.1186/ s12870-019-1715-0

Cao L, Zhao X (2014) Chinese experiences in breeding three-line, two-line and super hybrid rice. In: Yan W (ed) Rice: germplasm, genetics and improvement. https://doi.org/10.5772/56821

Carnahan HL, Erikson JR, Tseng ST, Rutger JN (1972) Outlook for hybrid rice in the USA. In: Rice breeding. International Rice Research Institute, Los Baños, pp 603-607

Chandirakala R, Kandasamy G, Thiyagarajan K (2008) Determination of fertility behaviour of thermo sensitive genic male sterile lines in rice. Oryza 45(2):110-114

Chandirakala R, Kandasamy G, Thiyagarajan K (2012) Genetic variability and combining ability for quality characters in two line hybrids in rice. Electron J Plant Breed 3(3):843-847

Chen LY, Xiao YH, Lei DY (2010) Mechanism of sterility and breeding strategies for photoperiod/thermo-sensitive genic male sterile rice. Rice Sci 17(3):161-167. https://doi.org/10.1016/ S1672-6308(09)60012-3

Chen J, Xu Y, Fei K, Wang R, He J, Fu L, Shao S, Li K, Zhu K, Zhang W, Wang Z, Yang J (2020) Physiological mechanism underlying the effect of high temperature during anthesis on spikelet-opening of photo-thermo-sensitive genic male sterile rice lines. Sci Rep 10(2210):24-27. https://doi.org/10.1038/s41598-020-59183-0

Cheng S, Sun Z, Si H, Zhuo L (1995) Response to photoperiod and temperature in photo-thermo period sensitive genic male sterile line Xinguang S (Oryza sativa L. subsp. indica). Chin J Rice Sci 9(2):87-91

Collard BCY, Beredo JC, Lenaerts B, Mendoza R, Santelices R, Lopena V, Verdeprado H, Raghavan C, Gregorio GB, Via L, Demon M, Biswas PS, Iftekharuddaula KM, Rahman MA, Cobb JN, Islam MR (2017) Revisiting rice breeding methods: evaluating the use of rapid generation advance (RGA) for routine rice breeding. Plant Prod Sci 20(4):337-352. https://doi.org /10.1080/1343943X.2017.1391705

Ding JH, Lu Q, Yidan OY, Mao HL, Zhang PB, Yao JL, Xu CG, Li XH, Xiao JH, Zhang QF (2012) A long noncoding RNA regulates photoperiod-sensitive male sterility, an essential component of hybrid rice. Proc Natl Acad Sci U S A 109:2654-2659

Dong NV, Subudhi PK, Luong PN, Quang VD, Quy TD, Zheng HG, Nguyen HT (2000) Molecular mapping of a rice gene conditioning thermosensitive genic male sterility using AFLP, RFLP and SSR techniques. Theor Appl Genet 100(5):727-734

FAO (Food and Agriculture Organization of the United Nations) (2020) FAOSTAT database. FAO, Rome. www.fao.org/faostat/en/\#data. Accessed 13 Jul 2020

Gao YZ (1991) Discovery and preliminary study of short photoperiod sensitive male-sterile rice. J Yichun Univ (Nat Sci) 1:1-5

Hien V, Yoshimura A (2015) Identifying map location and markers linked to thermosensitive genic male sterility gene in 103S line. J Sci Dev 13(3):331-336

Huang QC, Zhang XT (1991) CIS 28-10s, a new indica photoperiod sensitive genic male sterile rice. Int Rice Res Newsl 16(2):8-9 
Huang TY, Wang Z, Hu YG, Shi SP, Peng T, Chu XD, Liu DY (2008) Genetic analysis and primary mapping of $p m s 4$, a photoperiod-sensitive genic male sterility gene in rice (Oryza sativa). Rice Sci 15(2):153-156

Hussain A, Ali J, Siddiq E, Gupta V, Reddy U, Ranjekar P (2012) Mapping of tms 8 gene for temperature-sensitive genic male sterility (TGMS) in rice (Oryza sativa L.). Plant Breed 131:42-47

Jia J, Li C, Qu X, Wang Q, Deng Q, Weng M, Wang B (2000) Construction of genetic linkage map and mapping of thermo-sensitive genic male sterile gene tms 5 in rice. http://icgr.caas.net. cn/973/abstract/bwang.htm

Jia JH, Zhang DS, Li CY, Qu XP, Wang SW, Chamarerk V, Wang B (2001) Molecular mapping of the reverse thermo-sensitive genic male-sterile gene (rtms 1$)$ in rice. Theor Appl Genet 103(4):607-612

Jiang YM, Rong Y, Tao GX, Tang LJ (1997) Breeding of DiannongS2, a thermosensitive genic male sterile line with new cytoplasm from japonica rice. Southwest Chin J Agric Sci 3:21-24

Jiang J, Mou T, Yu H, Zhou F (2015) Molecular breeding of thermo-sensitive genic male sterile (TGMS) lines of rice for blast resistance using Pi2 gene. Rice 8(1):11. https://doi.org/10.1186/ s12284-015-0048-3

Joseph CA, Chen Z, Ma D, Zeng HL (2011) Analysis of short photoperiod-sensitive genic male sterility and molecular mapping of rpms $3(\mathrm{t})$ gene in rice (Oryza sativa $\mathrm{L}$.) using SSR markers. Genes Genomics 33:513-519. https://doi.org/10.1007/s13258-010-0074-x

Kadirimangalam SR, Kumar M, Saraswathi R, Mannonmani S, Raveendran M (2017) Study on critical sages and critical sterility point of thermo-sensitive genic male sterile lines of rice for two line hybrid production. Int J Curr Microbiol Appl Sci 6(5):2128-2135. https://doi. org/10.20546/ijcmas.2017.605.238

Kadirimangalam SR, Hifzur R, Saraswathi R, Kumar M, Raveendran M, Robin S (2019) Fine mapping and expression analysis of thermosensitive genic male sterility gene (tms) in rice (Oryza sativa L.). Plant Gene 19:100186. https://doi.org/10.1016/j.plgene.2019.100186

Khlaimongkhon S, Chakhonkaen S, Pitngam K, Ditthab K, Sangarwut N, Panyawut N, Wasinanon T, Mongkolsiriwatana C, Chunwongse J, Muangprom A (2019) Molecular markers and candidate genes for thermo-sensitive genic male sterile in rice. Rice Sci 26(3):147-156. https://doi. org/10.1016/j.rsci.2018.08.006

Kim YJ, Zhang D (2017) Molecular control of male fertility for crop hybrid breeding. Trends Plant Sci 23(1):53-65

Lang NT, Subudhi PK, Virmani SS, Brar DS, Khush GS, Li Z, Huang N (1999) Development of PCR-based markers for thermosensitive genetic male sterility gene tms $3(\mathrm{t})$ in rice (Oryza sativa $\mathrm{L}$.). Hereditas 131(2):121-127

Latha R, Thiyagarajan K (2010) Fertility alteration behaviour of thermosensitive genic male sterile lines in rice Oryza sativa L. Electron J Plant Breed 1(July):1118-1125

Latha R, Senthilvel S, Thiyagarajan K (2005) Critical temperature and stages of fertility alteration in thermo-sensitive genic male sterile lines of rice. In: Poster papers of the 4th international crop science congress, Brisbane, 2004

Lee DS, Chen LJ, Suh HS (2005) Genetic characterization and fine mapping of a novel thermo-sensitive genic male-sterile gene tms6 in rice (Oryza sativa L.). Theor Appl Genet 111(7):1271-1277

Li CQ (2009) Accelerating the development of japonica hybrid rice in China. In: Xie F, Hardy B (eds) Accelerating hybrid rice development. International Rice Research Institute, Laguna, pp 267-289

Li RB, Pandey MP, Sharma P (2005) Inheritance of thermosensitive genic male sterility in rice (Oryza sativa L.). Curr Sci 88(11):1805-1815

Li SF, Shen L, Hu P, Liu Q, Zhu XD, Qian Q, Wang KJ, Wang YX (2019) Developing diseaseresistant thermosensitive male sterile rice by multiplex gene editing. J Integr Plant Biol 61(12):1201-1205. https://doi.org/10.1111/jipb.12774 
Li C, Tao RF, Li Y, Duan MH, Xu JH (2020) Transcriptome analysis of the thermosensitive genic male-sterile line provides new insights into fertility alteration in rice (Oryza sativa). Genomics 112(3):2119-2129. https://doi.org/10.1016/j.ygeno.2019.12.006

Liu N, Shan Y, Wang FP, Xu CG, Peng KM, Li XH, Zhang QF (2001) Identification of an 85-kb DNA fragment containing $p m s 1$ a locus for photoperiod-sensitive genic male sterility in rice. Mol Gen Genomics 266:271-275

Liu X, Li X, Zhang X, Wang S (2010) Genetic analysis and mapping of a thermosensitive genic male sterility gene, tms6(t), in rice (Oryza sativa L.). Genome 53(2):119-124

Lopez MT, Tojinda T, Vanavichit A, Tragoonrung S (2000) Introgression of thermosensitive male sterility gene to aromatic Thai rice. In: Posters of the 4th International Rice Genetics Symposium, International Rice Research Institute, Laguna, Philippines, 22-27 October 2000

Lopez MT, Toojinda T, Vanavichit A, Tragoonrung S (2003) Microsatellite markers flanking the gene facilitated tropical TGMS rice line development. Crop Sci 43(6):2267-2271

Lu X, Wang J (1988) Fertility transformation and genetic behavior of Hubei photoperiod-sensitive genic male sterile rice. In: Hybrid rice. International Rice Research Institute, Los Baños, pp 129-138

Lu XG, Zhang ZG, Maruyama K, Virmani SS (1994) Current status of two-line method of hybrid rice breeding. In: Virmani SS (ed) Hybrid rice technology: new developments and future prospects. International Rice Research Institute, Manila, pp 37-49

Lu Q, Li XH, Guo D, Xu CG, Zhang Q (2005) Localization of pms3, a gene for photoperiodsensitive genic male sterility, to a 28.4-kb DNA fragment. Mol Gen Genomics 273(6):507-511

Luo Y, Tingchen M, Teo J, Luo Z, Li Z, Yang J, Yin Z (2020) Marker-assisted breeding of thermosensitive genic male sterile line $1892 \mathrm{~S}$ for disease resistance and submergence tolerance. Rice Sci 27:89-98

Mahalingam A, Saraswathi R, Ramalingam J, Jayaraj T (2013) Genetics of floral traits in cytoplasmic male sterile (CMS) and restorer lines of hybrid rice (Oryza sativa L.). Pak J Bot 45(6):1897-1904

Manonmani S, Pushpam R, Robin S (2016) Stability of TGMS lines under different temperature regimes for pollen sterility. J Rice Res 9(1):17-19

Maruyama K, Araki H, Amano E (1990) Enhancement of out-crossing habits of rice plant by mutation breeding. Gamma Field Symp 29:11-25

Maruyama K, Araki H, Kato H (1991) Thermosensitive genetic male sterility induced by irradiation. In: Rice genetics II. International Rice Research Institute, Manila, pp 227-235

Mei MH, Dai XK, Xu CG, Zhang QF (1999) Mapping and genetic analysis of genes for photoperiod-sensitive genic male sterility in rice using the original mutant Nongken 58S. Crop Sci 39:1711-1715

Mishra A, Bohra A (2018) Non-coding RNAs and plant male sterility: current knowledge and future prospects. Plant Cell Rep:1-15

Mou TM, Xing-Gui L, Hoan NT, Virmani SS (2003) Two-line hybrid rice breeding in and outside China. In: Virmani SS, Mao CX, Hardy B (eds) Hybrid rice for food security, poverty alleviation, and environmental protection. Proceedings of the 4th international symposium on hybrid rice, Hanoi, 14-17 May 2002. International Rice Research Institute, Manila, pp 31-52

Nas TMS, Sanchez DL, Diaz MGQ, Mendioro MS, Virmani SS (2005) Pyramiding of thermosensitive genetic male sterility (TGMS) genes and identification of a candidate tms 5 gene in rice. Euphytica 145:67-75

Oard JH, Hu J (1995) Inheritance and characterization of pollen fertility in photoperiodically sensitive rice mutants. Euphytica 82:17-23

Oka HT, Morishima H (1967) The ancestors of cultivated rice and their evolution. Department of Applied Genetics, National Institute of Genetics, Japan. p 145

Pan Y, Li Q, Wang Z, Wang Y, Ma R, Zhu L, He G, Chen R (2014) Genes associated with thermosensitive genic male sterility in rice identified by comparative expression profiling. BMC Genomics 15(1):1114. https://doi.org/10.1186/1471-2164-15-1114 
Pang Y, Ali J, Wang X, Franje NJ, Revilleza JE, Xu J, Li Z (2016) Relationship of rice grain amylose, gelatinization temperature and pasting properties for breeding better eating and cooking quality of rice varieties. PLoS One 11(12):e0168483. https://doi.org/10.1371/journal. pone. 0168483

Peng HF, Zhang ZF, Wu B, Chen XH, Zhang GQ, Zhang ZM, Lu YP (2008) Molecular mapping of two reverse photoperiod-sensitive genic male sterility genes (rpms 1 and $r p m s 2)$ in rice (Oryza sativa $\mathrm{L}$.). Theor Appl Genet 118(1):77-83

Peng HF, Chen XH, Lu YP, Peng YF, Wan BH, Chen ND, Wu B, Xin SP, Zhang GQ (2010) Fine mapping of a gene for non-pollen type thermosensitive genic male sterility in rice (Oryza sativa L.). Theor Appl Genet 120:1013-1020

Pitnjam K, Chakhonkaen S, Toojinda T, Muangprom A (2008) Identification of a deletion in tms2 and development of gene-based markers for selection. Planta 228:813-822. https://doi. org/10.1007/s00425-008-0784-3

Qi Y, Liu Q, Zhang L, Mao B, Yan D, Jin Q, He Z (2014) Fine mapping and candidate gene analysis of the novel thermo-sensitive genic male sterility tms $9-1$ gene in rice. Theor Appl Genet 127(5):1173-1182

Rahul Roy R, Kumaresan D (2019) Genetic variability and association studies for yield and floral traits in temperature sensitive male sterile lines (TGMS) of rice (Oryza sativa $\mathrm{L})$. Electron $\mathrm{J}$ Plant Breed 10(3):1200-1209. https://doi.org/10.5958/0975-928X.2019.00152.2

Rajesh T, Radhakrishnan VV, Pressana KK, Francies RM, Sreenivasan E, Ibrahim KK, Latha A (2017) Critical stages of thermo-sensitive genic male sterile lines of rice in Kerala. ORYZA Int J Rice 54(4):401-406. https://doi.org/10.5958/2249-5266.2017.00054.6

Ramakrishna S, Mallikarjuna SBP, Mishra B, Virakthamath BC, Illyas Ahmed M (2006) Characterization of thermo sensitive genetic male sterile lines for temperature sensitivity, morphology and floral biology in rice (Oryza sativa L.). Asian J Plant Sci 5(3):421-428. https:// doi.org/10.3923/ajps.2006.421.428

Reddy OUK, Siddiq EA, Sarma NP, Ali J, Hussain AJ, Nimmakayala P, Reddy AS (2000) Genetic analysis of temperature-sensitive male sterility in rice. Theor Appl Genet 100(5):794-801

Rutger JN, Schaeffer GW (1989) An environmentally sensitive genetic male sterile mutant in rice. In: Annual meeting of the American Society of Agronomy, Las Vegas, Nev., USA. Agron. Abstr. p 98

Salgotra RK, Gupta BB, Ahmed MI (2012) Characterization of thermo-sensitive genic male sterility (TGMS) rice genotypes: (Oryza sativa L.) at different altitudes. Aust J Crop Sci 6(6):957-962

Sanchez DL, Virmani SS (2005) Identification of thermosensitive genic male-sterile lines with low critical sterility point for hybrid rice breeding. Philipp J Crop Sci 30:19-28

Sasikala R, Kalaiyarasi R, Paramathama M (2015) Influence of weather factors on fertility alteration in thermosensitive genic male sterile lines of rice (Oryza sativa L.). Int J Trop Agric 33(2):773-779. https://doi.org/10.13140/RG.2.2.24654.41280

Shen Y, Gao M, Cai Q (1994) A novel environment induced genic male sterile (EGMS) mutant in indica rice. Euphytica 76:89-96

Sheng Z, Wei X, Shao G, Chen M, Song J, Tang S, Chen L (2013) Genetic analysis and fine mapping of $t m s$, a novel thermosensitive genic male-sterile gene in rice (Oryza sativa L.). Plant Breed 132(2):159-164

Sheng Z, Tang L, Shao G, Xie L, Jiao G, Tang S, Hu P (2015) The rice thermo-sensitive genic male sterility gene tms 9: pollen abortion and gene isolation. Euphytica 203(1):145-152

Shi MS (1981) Report on breeding and application of two-line system in later japonica. Hubei Agric Sci 7:1-3

Shi MS (1985) The discovery and study of the photosensitive recessive male sterile rice (Oryza sativa L. subsp. japonica). Sci Agric Sin 2:44-48

Shi MS, Deng JY (1986) The discovery, determination and utilization of Hubei photosensitive genic male sterile rice (Oryza sativa L. subsp. japonica). Acta Genet Sin 13(2):107-112 
Shukla SK, Pandey MP (2008) Combining ability and heterosis over environments for yield and yield components in two-line hybrids involving thermosensitive genic male sterile lines in rice (Oryza sativa L.). Plant Breed 127(1):28-32. https://doi.org/10.1111/j.1439-0523.2007.01432.x

Si HM, Fu YP, Liu WZ, Sun ZX, Hu GC (2012) Pedigree analysis of photoperiod thermo-sensitive genic male sterile rice. Acta Agron Sin 38:394-407

Siddiq EA, Ali J (1999) Innovative male sterility systems for exploitation of hybrid vigour in crop plants: environment sensitive genic male sterility system. Proc Indian Natl Sci Acad B 65:331-350

Song FS, Ni JL, Qian YL, Li L, Ni DH, Yang JB (2016) Development of SNP-based dCAPS markers for identifying male sterile gene tms5 in two-line hybrid rice. Genet Mol Res 15(3). https:// doi.org/10.4238/gmr.15038512

Soundararaj AK, Ali AJ, Thiyagarajan P, Arumugachamy S (2002) Prospects of two-line hybrid rice breeding in Tamil Nadu, India. Int Rice Res Notes 27(1):1

Subudhi PK, Borkakati RP, Virmani SS, Huang N (1997) Identification of RAPD markers linked to rice thermosensitive genetic male sterility gene by bulk segregant analysis. Rice Genet Newsl 12:228-231

Swaminathan MS, Siddiq EA, Sharma SD (1972) Outlook for hybrid rice in India. Rice breeding. International Rice Research Institute, Laguna, pp 609-613

Tan ZC, Li YY, Chen LB, Zhou GQ (1990) Studies on ecological-adaptability of dual purpose line Annong S-1. Hybrid Rice 3:35-38

Vinodhini M, Saraswathi R, Viswanathan PL, Raveendran M (2019) Studies on sterility behaviour in thermo-sensitive genic male sterile lines of rice. Int J Chem Stud 7(6):55-61

Viraktamath BC, Virmani SS (2001) Expression of thermosensitive genic male sterility in rice under varying temperature situations. Euphytica 122(1):137-143. https://doi.org/10.102 3/A: 1012607608792

Virmani SS (1992) Transfer and induction of thermosensitive genic male sterile mutant in indica rice. In: Proceedings of the second international symposium on hybrid rice, 21-25 April 1992. International Rice Research Institute, Manila

Virmani SS (1994) Heterosis and hybrid rice breeding. Monographs on theoretical and applied genetics. Springer, Berlin, $192 \mathrm{p}$

Virmani SS, Voc PC (1991) Induction of photo- and thermo-sensitive male sterility in indica rice. Agron Abstr 119

Virmani SS, Sun ZX, Mou TM, Ali J, Mao CX (2003) Two-line hybrid rice breeding manual. International Rice Research Institute, Los Banos, p 88

Wang H, Deng XW (2018) Development of the "third-generation" hybrid rice in China. Genomics Proteomics Bioinformatics 16(6):393-396. https://doi.org/10.1016/j.gpb.2018.12.001

Wang B, Xu WW, Wang JZ et al (1995) Tagging and mapping the thermo-sensitive genic malesterile gene in rice (Oryza sativa L.) with molecular markers. Theor Appl Genet 91:1111-1114. https://doi.org/10.1007/BF00223928

Wang YG, Xing QH, Deng QY, Liang FS, Yuan LP, Weng ML, Wang B (2003) Fine mapping of the rice thermo-sensitive genic male-sterile gene tms5. Theor Appl Genet 107(5):917-921

Wang C, Zhang P, Ma Z, Zhang M, Sun G, Ling D (2004) Development of a genetic marker linked to a new thermo-sensitive male sterile gene in rice (Oryza sativa L.). Euphytica 140(3):217-222

Wang K, Peng X, Ji Y, Yang P, Zhu Y, Li S (2013) Gene, protein, and network of male sterility in rice. Front Plant Sci 4:92. https://doi.org/10.3389/fpls.2013.00092

Wang SY, Tian QY, Zhou SQ, Mao DD, Chen LB (2019) A quantitative proteomic analysis of the molecular mechanism underlying fertility conversion in thermo-sensitive genetic male sterility line AnnongS-1. BMC Plant Biol 19:65. https://doi.org/10.1186/s12870-019-1666-5

Wongpatsa U, Kaveeta L, Sriwongchai T, Khamsuk O (2014) Effects of temperature on male sterility of two inbred lines of hybrid rice. Kasetsart J Nat Sci 48(4):525-533

Worldometer (2020). https://www.worldometers.info/world-population/\#/table-forecast. Accessed $13 \mathrm{Jul} 2020$ 
Xu J, Wang B, Wu Y, Du P, Wang J, Wang M, Liang G (2011) Fine mapping and candidate gene analysis of ptgms 2-1, the photoperiod-thermo-sensitive genic male sterile gene in rice (Oryza sativa L.). Theor Appl Genet 122(2):365-372

Yamaguchi Y, Hirasawa H, Minami M, Ujihara A (1997) Linkage analysis of thermosensitive genic male sterility gene, tms-2 in rice (Oryza sativa L.). Jpn J Breed 47(4):371-373

Yang QH, Zhu J (1996) Breeding of go543S, an indica PTGMS rice with its sterility induced by short day-length and low temperature. Hybrid Rice 1:9-10

Yang RC, Wang NY, Mang K, Chau Q, Yang RR, Chen S (1990) Preliminary studies on application of indica photo-thermo genic male sterile line 5460S in hybrid rice breeding. Hybrid Rice $1: 32-34$

Yang YZ, Tang PL, Yang WC, Liu AM, Chen YQ, Ling WB, Shi TB (2000) Breeding and utilization of TGMS line Zhu1S in rice. Hybrid Rice 15(2):6-9

Yang ZY, Zhang GL, Zhang CH, Chen JJ, Wang HQ, Zhang JJ, Yan Z (2002) Breeding of fine quality PTGMS line Guangzhan 63S in medium indica rice. Hybrid Rice 17(4):4-6

Yang QK, Liang CY, Zhuang W, Jun Li J, Deng HB, Deng QY, Wang B (2007) Characterization and identification of the candidate gene of rice thermo-sensitive genic male sterile gene tms 5 by mapping. Planta 225:321-330

Yao L, Zhang Y, Liu C, Liu Y, Wang Y, Liang D, Liu J, Sahoo G, Kelliher T (2018) OsMATL mutation induces haploid seed formation in indica rice. Nat Plants 4:530-533. https://doi. org/10.1038/s41477-018-0193-y

Yiming J (1988) Studies on the effect of high temperature on fertility of the male sterile lines in Dian-type hybrid rice [J]. J Yunnan Agric Univ 2000

Yu J, Han J, Kim YJ, Song M, Yang Z, He Y, Fu R, Luo Z, Hu J, Liang W, Zhang D (2017) Two rice receptor-like kinases maintain male fertility under changing temperatures. Proc Natl Acad Sci U S A 114(46):12327-12332. https://doi.org/10.1073/pnas.1705189114

Yuan LP (1987) Strategic assumption of hybrid rice breeding. Hybrid Rice 1:1-3

Yuan LP (2014) Development of hybrid rice to ensure food security. Rice Sci 21(1):1-2. https:// doi.org/10.1016/S1672-6308(13)60167-5

Zhang Z, Zeng H, Yang J, Yuan S, Zhang D (1994) Conditions inducing fertility alteration and ecological adaptation of photoperiod-sensitive genic male-sterile rice. Field Crops Res 38(2):111120. https://doi.org/10.1016/0378-4290(94)90005-1

Zhang H, Xu CX, He Y, Zong J, Yang X, Si HM, Sun ZX, Hu JP, Liang WQ, Zhang DB (2013) Mutation in CSA creates a new photoperiod-sensitive genic male sterile line applicable for hybrid rice seed production. Proc Natl Acad Sci U S A 110:76-81

Zhou YF, Zhang XY, Xue QZ (2011) Fine mapping and candidate gene prediction of the photoperiod and thermo-sensitive genic male sterile gene $\operatorname{pms} 1(\mathrm{t})$ in rice. J Zhejiang Univ Sci B 12(6):436-447

Zhou H, Liu Q, Li J, Jiang D, Zhou L, Wu P, Chen L (2012) Photoperiod-and thermo-sensitive genic male sterility in rice are caused by a point mutation in a novel noncoding RNA that produces a small RNA. Cell Res 22(4):649-660

Zhou H, Zhou M, Yang Y et al (2014) RNase ZS1 processes UbL40 mRNAs and controls thermosensitive genic male sterility in rice. Nat Commun 5:4884. https://doi.org/10.1038/ ncomms5884

Zhou H, He M, Li J, Chen L, Huang Z, Zheng S, Zhu L, Ni E, Jiang D, Zhao B, Zhuang C (2016) Development of commercial thermo-sensitive genic male sterile rice accelerates hybrid rice breeding using the CRISPR/Cas9-mediated TMS5 editing system. Sci Rep 6:37395. https:// doi.org/10.1038/srep37395 
Open Access This chapter is licensed under the terms of the Creative Commons Attribution 4.0 International License (http://creativecommons.org/licenses/by/4.0/), which permits use, sharing, adaptation, distribution and reproduction in any medium or format, as long as you give appropriate credit to the original author(s) and the source, provide a link to the Creative Commons license and indicate if changes were made.

The images or other third party material in this chapter are included in the chapter's Creative Commons license, unless indicated otherwise in a credit line to the material. If material is not included in the chapter's Creative Commons license and your intended use is not permitted by statutory regulation or exceeds the permitted use, you will need to obtain permission directly from the copyright holder. 